

\title{
High performance reactive transport simulations examining the effects of thermal, hydraulic, and chemical (THC) gradients on fluid injectivity at carbonate CCUS reservoir scales
}

\author{
Benjamin M.Tutolo ${ }^{a, *}$, Xiang-Zhao Konga,b,c, William E. Seyfried, Jr. ${ }^{a}$, Martin O. Saar $^{a, b}$ \\ ${ }^{a}$ Department of Earth Sciences, University of Minnesota, Minneapolis, MN, 55455 USA \\ ${ }^{b}$ Department of Earth Sciences, ETH-Zürich, Zürich, Switzerland \\ ${ }^{c}$ School of Civil Engineering, The University of Queensland, St. Lucia, QLD, 4072, Australia
}

\begin{abstract}
Carbonate minerals and $\mathrm{CO}_{2}$ are both considerably more soluble at low temperatures than they are at elevated temperatures. This inverse solubility has led a number of researchers to hypothesize that injecting low-temperature (i.e., less than the background reservoir temperature) $\mathrm{CO}_{2}$ into deep, saline reservoirs for $\mathrm{CO}_{2}$ Capture, Utilization, and Storage (CCUS) will dissolve $\mathrm{CO}_{2}$ and carbonate minerals near the injection well and subsequently exsolve and re-precipitate these phases as the fluids flow into the geothermally warm portion of the reservoir. In this study, we utilize high performance computing to examine the coupled effects of cool $\mathrm{CO}_{2}$ injection and background hydraulic head gradients on reservoir-scale mineral volume changes. We employ the fully coupled reactive transport simulator PFLOTRAN with calculations distributed over up to 800 processors to test 21 scenarios designed to represent a range of reservoir depths, hydraulic head gradients, and $\mathrm{CO}_{2}$ injection rates and temperatures. In the default simulations, $50^{\circ} \mathrm{C} \mathrm{CO}_{2}$ is injected at a rate of $50 \mathrm{~kg} / \mathrm{s}$ into a $200 \mathrm{bar}, 100^{\circ} \mathrm{C}$ calcite or dolomite reservoir. By comparing these simulations with others run at varying conditions, we show that the effect of cool $\mathrm{CO}_{2}$ injection on reservoir-scale mineral volume changes tends to be relatively minor. We conclude that the low heat capacity of $\mathrm{CO}_{2}$ effectively prevents low-temperature $\mathrm{CO}_{2}$ injection from decreasing the temperature across large portions of the simulated carbonate reservoirs. This small thermal perturbation, combined with the low relative permeability of brine within the supercritical $\mathrm{CO}_{2}$ plume, yields limited dissolution and precipitation effects directly attributable to cool $\mathrm{CO}_{2}$ injection. Finally, we calculate that relatively high water-to-rock ratios, which may occur over much longer CCUS reservoir lifetimes or in materials with sufficiently high brine relative permeability within the supercritical $\mathrm{CO}_{2}$ plume, would be required to substantially affect injectivity through thermally-induced mineral dissolution and precipitation. Importantly, this study shows the utility of reservoir scale-reactive transport simulators for testing hypotheses and placing laboratory-scale observations into a CCUS reservoir-scale context.
\end{abstract}




\section{Introduction}

Geological Carbon Capture, Utilization, and Storage (CCUS) has the potential to prevent large volumes of the heat-trapping greenhouse gas carbon dioxide $\left(\mathrm{CO}_{2}\right)$ from entering the atmosphere and exacerbating global climate change (e.g., Pacala and Socolow, 2004; IPCC, 2005; Benson and Cole, 2008; DePaolo et al., 2013; IPCC, 2014). Although deep geologic $\mathrm{CO}_{2}$ storage has been considered for some time as a tactic for mitigating the detrimental effects of climate change, the scale of its implementation has been largely limited by its high associated costs (Eccles et al., 2009; Randolph and Saar, 2011b). Researchers have suggested that both its economic feasibility and degree of implementation can be dramatically improved if the stored $\mathrm{CO}_{2}$ is utilized for ancillary benefits, such as Enhanced Oil Recovery (EOR, e.g., Gozalpour et al. (2005); Saar et al. (2014b)), $\mathrm{CO}_{2}$-based hydraulic fracturing (e.g., Tao and Clarens (2013); Zhou and Burbey (2014)), and/or energy extraction (e.g., $\mathrm{CO}_{2}$-Enhanced Geothermal Systems ( $\mathrm{CO}_{2}$-EGS, e.g., Brown (2000); Pruess (2006); Lo Ré et al. (2014)) and $\mathrm{CO}_{2}$ Plume Geothermal (CPG, Randolph and Saar (2011a); Saar et al. (2012, 2013, 2014a,b)).

A range of reservoir lithologies are considered for CCUS installation. To date, hydrocarbon reservoirs comprised of siliciclastics and/or carbonate minerals have been a large focus of CCUS research, particularly because of their widespread occurrence, known ability to securely trap light, non-aqueous phases, and the economic benefits of $\mathrm{CO}_{2}$-EOR (e.g., Blunt et al., 1993; Malik et al., 2000). Moreover, researchers have proposed combined CPG and EOR in feasible reservoirs, which could offset some of the $\mathrm{CO}_{2}$ emissions associated with hydrocarbon extraction and refining processes while producing heat and/or electricity (Randolph, 2011; Freifeld et al., 2013; Adams et al., 2014). Nonetheless, if CCUS is going to make an impact on global $\mathrm{CO}_{2}$ emissions, all feasible reservoirs-including those that did not previously contain an economically viable hydrocarbon resource- must be considered for CCUS installation.

Because CCUS reservoir temperatures are inherently elevated with respect to surface conditions (e.g., Saar, 2011), thermal gradients are likely to develop as cool $\mathrm{CO}_{2}$ is injected (Lu and Connell, 2008; André et al., 2010; Han et al., 2010; Rayward-Smith and Woods, 2011; Randolph and Saar, 2011a; Singh et al., 2012; Jobard et al., 2013; Luhmann et al., 2013; Ruan et al., 2013; Tutolo et al., 2014b; Garapati et al., 2015). Although cool $\mathrm{CO}_{2}$ may exchange energy with the geothermally warm material surrounding the well casing as it flows down the injection borehole

*Corresponding author: Phone: (612)625-3928, Email: tutol001@umn.edu 
and undergo Joule-Thomson heating and cooling upon compression and decompression, respectively, calculations show that bottomhole $\mathrm{CO}_{2}$ temperatures typically remain significantly depressed relative to the reservoir (Oldenburg, 2007; Lu and Connell, 2008; Rayward-Smith and Woods, 2011; Garapati et al., 2015). Moreover, in some instances, particularly in the case of $\mathrm{CO}_{2}$-based geothermal energy systems, lower injection wellhead $\mathrm{CO}_{2}$ temperatures are actually sought in order to boost system power output (e.g., Pruess, 2006; Randolph and Saar, 2011a; Adams et al., 2014). In all cases, the lower temperatures near the injection well can lead to solubility gradients and coupled redistribution of reservoir porosity and permeability (e.g., Luhmann et al., 2013; Jobard et al., 2013; Tutolo et al., 2014b).

Deep, geothermally-heated, subsurface reservoirs are characterized by a range of background hydraulic head gradients and groundwater flow velocities (e.g., Saar, 2011). The magnitude, direction, and length scales of these natural flow regimes are dependent upon the permeability, porosity, and pressure and temperature structure of the particular reservoir. The presence of background hydraulic head gradients in subsurface aquifers can also determine the effectiveness of supercritical $\mathrm{CO}_{2}$ storage, particularly by the capillary trapping mechanism (MacMinn et al., 2010). Furthermore, where required, $\mathrm{CO}_{2}$-based geothermal energy reservoir operators may also engineer hydraulic head gradients by pumping fluids into or out of the reservoir to manage the flow of $\mathrm{CO}_{2}$ in the subsurface and its thermal exchange with the reservoir (Buscheck et al., 2011, 2012; Elliot et al., 2013).

Ideal CCUS reservoirs have optimized permeability structures that will allow for sufficient $\mathrm{CO}_{2}$ injectivities and/or promote efficient extraction of geothermal heat from the subsurface. Ideal reservoirs for $\mathrm{CO}_{2}$-based geothermal operations will maintain high enough permeabilities to ensure sufficient $\mathrm{CO}_{2}$ injectivities and heat extraction from the subsurface without creating short-circuit, high permeability flow paths between injection and production wells (e.g., Harlow and Pracht, 1972; Randolph and Saar, 2011c; Tutolo et al., 2015a). However, as cool $\mathrm{CO}_{2}$ is injected into CCUS reservoirs, it will displace and dissolve into formation waters, reduce reservoir temperature and $\mathrm{pH}$, and enhance mineral reactivity (Kharaka et al., 2006; Benson and Cole, 2008; Kong and Saar, 2013). In CCUS formations containing carbonate minerals, their unique quality of decreasing solubility with increasing temperature, combined with similar behavior for $\mathrm{CO}_{2}$ solubility, will tend to redistribute porosity and permeability as formation waters flow away from the injection well (André et al., 2010; Tutolo et al., 2014b). Depending on the spatial distribution of these mass and flow property changes, they may lead to positive or negative feedbacks on geothermal energy production from a particular reservoir (Adams et al., 2014) 
A number of experimental studies have been conducted in order to examine the effects of low-temperature $\mathrm{CO}_{2}$ injection into CCUS reservoirs (e.g., Luhmann et al., 2013; Jobard et al., 2013; Tutolo et al., 2014b). Experimental results generally illustrate that thermally-induced changes in $\mathrm{CO}_{2}$ and carbonate solubility can substantially reorganize porosity and permeability in laboratory-scale samples. Reductions in $\mathrm{CO}_{2}$ solubility appear to have a more pronounced effect, and can lead to considerable (i.e., up to several orders of magnitude in unconsolidated sediments (Luhmann et al., 2013)) reductions in permeability as a result of $\mathrm{CO}_{2}$ exsolution, grain displacement, and the onset of two-phase flow. Reductions in carbonate solubility and the resultant precipitation tend to have a markedly less pronounced effect, with porosity typically being reduced by several percent (Jobard et al., 2013; Tutolo et al., 2014b).

Although these studies suggest a potentially significant impact of cool $\mathrm{CO}_{2}$ injection on CCUS reservoir injectivity, the effects of injection, dissolution, precipitation, and exsolution, when coupled at the reservoir scale, may differ from the results of these studies conducted at much smaller scales, particularly in the context of $\mathrm{CO}_{2}$-EOR, $\mathrm{CO}_{2}$-EGS, and CPG. For example, in the experiments presented by both Luhmann et al. (2013) and Tutolo et al. (2014b), $\mathrm{CO}_{2^{-}}$ rich $\mathrm{H}_{2} \mathrm{O}$ was injected into experimental cores, and their observed permeability reductions were predominantly the result of thermally-driven $\mathrm{CO}_{2}$ exsolution. In CCUS reservoirs, only a small fraction of the injected $\mathrm{CO}_{2}$ will dissolve into the reservoir brine, and much of it will remain in the supercritical phase, with the specific dissolution behavior depending on the permeability heterogeneity structure of the reservoir (Farajzadeh et al., 2011; Kong and Saar, 2013). Any $\mathrm{CO}_{2}$ exsolution from the water phase will therefore likely occur in close proximity to the free $\mathrm{CO}_{2}$ phase, and $\mathrm{CO}_{2}$ will be able to coalesce with the larger $\mathrm{CO}_{2}$ plume, depending on the capillary forces it experiences. In consequence, the permeability reduction associated with the transition from one- to two-phase flow observed in the core-scale experiments of Luhmann et al. (2013) and Tutolo et al. (2014b), which was the result of thermally-driven $\mathrm{CO}_{2}$ exsolution, may be less significant at the CCUS reservoir scale.

Several numerical investigations have attempted to place the effects of cool $\mathrm{CO}_{2}$ injection into a reservoir-scale context (e.g., André et al., 2010; Singh et al., 2012; Zhao and Cheng, 2014). Specifically, André et al. (2010) used the reactive transport simulator TOUGHREACT (Xu et al., 2006) in order to explore the effect of low-temperature $\mathrm{CO}_{2}$ injection into the Dogger Aquifer, France. Their simulations illustrated the sensitivity of carbonate mineral and $\mathrm{CO}_{2}$ solubilities to cool $\mathrm{CO}_{2}$ injection, and showed that significant amounts of carbonates may dissolve and re-precipitate in CCUS reservoirs. They attributed much of their observed precipitation to desiccation processes (i.e., $\mathrm{H}_{2} \mathrm{O}$ dissolution into supercritical $\mathrm{CO}_{2}$ ), rather than thermal pro- 
cesses, however. Their simulations employed a three-dimensional (3D) but radially symmetric domain, which allowed for reduced, two-dimensional computational complexity but, unfortunately, lacked the ability to capture processes such as background hydraulic head gradients and changes in parameters (e.g., mineral composition and volume, porosity, permeability) in the third dimension.

Until recently, the computationally intensive nature of large-scale, 3D simulations of CCUS reservoirs has effectively prohibited researchers from performing them. The recent development of the massively parallel reactive transport simulator PFLOTRAN (Hammond et al., 2012; Lichtner et al., 2013) for simulating CCUS reservoirs has made such simulations increasingly feasible, particularly whenever researchers have access to high-performance supercomputing clusters (e.g., Lu and Lichtner, 2005; Mills et al., 2009; Navarre-Sitchler et al., 2013). In this study, we slightly modify and utilize PFLOTRAN to examine the hydrogeochemical effects of thermal and hydraulic head gradients in carbonate CCUS reservoirs. We specifically focus on the effects of cool $\left(50^{\circ} \mathrm{C}\right) \mathrm{CO}_{2}$ injection into geothermally warm $\left(100^{\circ} \mathrm{C}\right)$ reservoirs with uniform background hydraulic head gradients. We quantify the volumes and spatial distribution of carbonate mineral dissolution and precipitation as well as the coupled spatial, temporal, and thermal evolution of the injected supercritical $\mathrm{CO}_{2}$ plume and reservoir fluid. The simulations presented here allow us to place prior experimental and numerical observations into a reservoirscale context while constraining the potential impacts of both thermal and hydraulic head gradients on important reservoir hydrogeochemical parameters.

\section{Methods}

\subsection{Model Formulation}

The simulations we present here utilize the reactive transport simulator PFLOTRAN (Hammond et al., 2012; Lichtner et al., 2013), which employs the integrated finite volume approach to discretize the spatial domain and fully-implicit backward-Euler time differencing (Hammond et al., 2007). In all simulations, the domain volume is set to $3.6 \times 10^{8} \mathrm{~m}^{3}$, which is divided into 90,000 elements with horizontal dimensions of $20 \mathrm{~m}$ x $20 \mathrm{~m}$ and vertical dimensions of $10 \mathrm{~m}$ for the $50 \mathrm{~kg} / \mathrm{s}$ injection simulations (Fig. 1). In the $4 \mathrm{~kg} / \mathrm{s}$ injection simulations, the number of elements is reduced to 48,000 by changing the vertical grid spacing to $18.75 \mathrm{~m}$. Reservoir thickness in all simulations is fixed at $150 \mathrm{~m}$ along the vertical coordinate, but the horizontal coordinates are varied to accommodate $\mathrm{CO}_{2}$ plume flow paths and shapes characteristic of the applied hydraulic head gradient. Specifically, because their higher flow velocities tend to significantly elongate the $\mathrm{CO}_{2}$ plume in the down-gradient direction, the $0.1 \mathrm{~m} / \mathrm{m}$ and $0.05 \mathrm{~m} / \mathrm{m}$ 


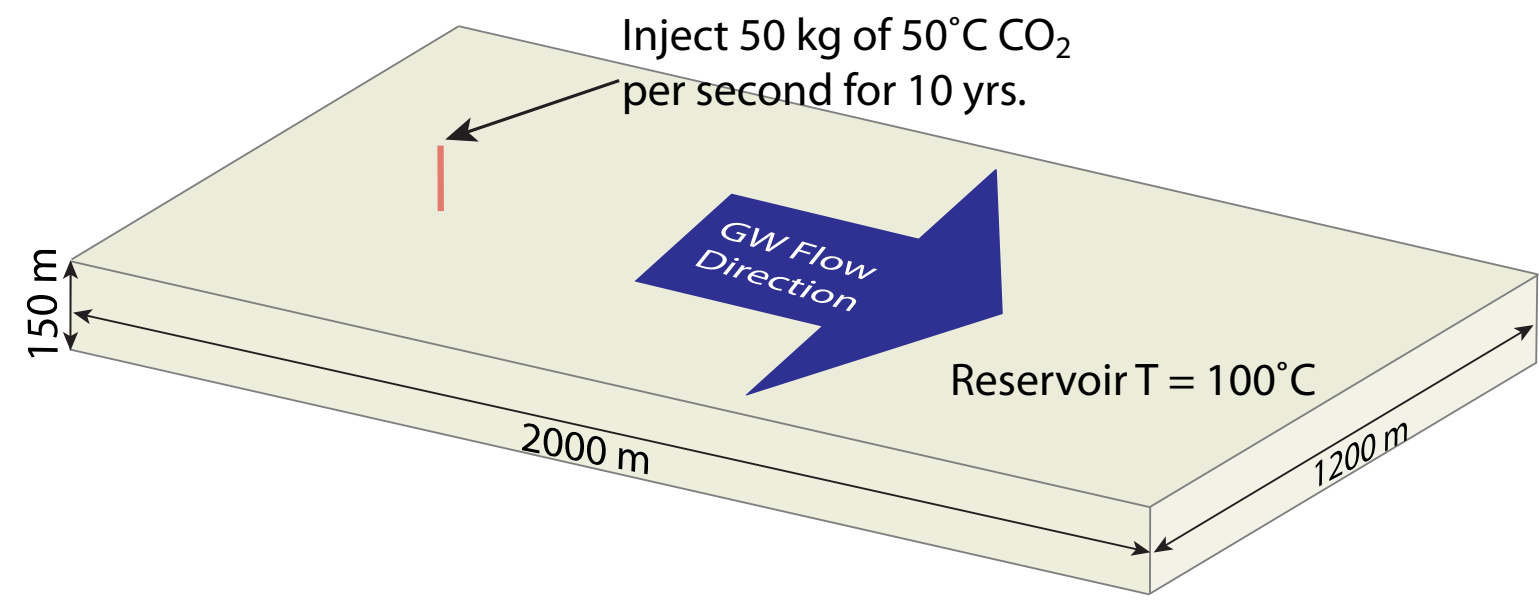

Figure 1: Reactive transport simulations illustrate the effects of cool $\mathrm{CO}_{2}$ injection into $100^{\circ} \mathrm{C}$ calcite and dolomite CCUS reservoirs with background hydraulic head gradients of $0.01,0.05$, and $0.1 \mathrm{~m} / \mathrm{m}$. All simulated reservoirs have a constant permeability of $10^{-13} \mathrm{~m}^{2}$, which translates to Darcy velocities of 1.1, 5.5, and 10.9 $\mathrm{m} / \mathrm{yr}$, respectively, for these hydraulic head gradients. Here, a schematic demonstrates the dimensions of the simulated reservoir for the 0.05 and $0.1 \mathrm{~m} / \mathrm{m}$ hydraulic head gradient scenarios. Due to broader $\mathrm{CO}_{2}$ plume dimensions caused by lower flow velocities, the dimensions of the reservoir in the $0.01 \mathrm{~m} / \mathrm{m}$ hydraulic head gradient scenario are more square-shaped, at $1600 \mathrm{~m}$ in the primary flow direction and $1500 \mathrm{~m}$ in the direction perpendicular to flow. Although we indicate that $50 \mathrm{~kg}$ of $50^{\circ} \mathrm{C} \mathrm{CO}_{2}$ is injected per second into this schematic reservoir, simulations employing lower injection rates $(4 \mathrm{~kg} / \mathrm{s})$ and higher injection temperatures $\left(100^{\circ} \mathrm{C}\right)$ are also presented (Table 3). In all simulations presented in this study, the reservoir volume is $3.6 \times 10^{8} \mathrm{~m}^{3}$. Scenarios with an injection rate of $50 \mathrm{~kg} / \mathrm{s}$ employ 90,000 $20 \mathrm{~m}$ x $20 \mathrm{~m}$ x $10 \mathrm{~m}$ elements and simulations with an injection rate of $4 \mathrm{~kg} / \mathrm{s}$ employ 48,000 $20 \mathrm{~m}$ x $20 \mathrm{~m}$ x $18.75 \mathrm{~m}$ elements (See Sect. 2.1). 
simulations contain 100 elements in the dominant flow direction and 60 elements perpendicular to flow. Likewise, because the $0.01 \mathrm{~m} / \mathrm{m}$ simulations tend to yield $\mathrm{CO}_{2}$ plumes that expand both latitudinally and longitudinally throughout the reservoir, they contain 80 elements in the dominant flow direction and 75 elements perpendicular to flow. In addition, the injection well is placed according to the hydraulic head gradient employed, in order to attempt to prevent injected $\mathrm{CO}_{2}$ from escaping through the upstream boundary of the reservoir. This provision is necessary because the boundary conditions employed here dictate that once $\mathrm{CO}_{2}$ exits the system, it will not return. In the $0.01,0.05$, and $0.1 \mathrm{~m} / \mathrm{m}$ hydraulic head gradient reservoirs, $\mathrm{CO}_{2}$ is injected 700,400 , and $200 \mathrm{~m}$ from the upstream boundary, respectively. The upper and lower domain boundaries are assigned no-flow boundary conditions to simulate impermeable caprock layers, but fluid and heat are allowed to flow through the hydrostatically equilibrated side boundaries of the modeled domain.

Several dolomite reservoir simulations (not presented here) were additionally performed with $10 \mathrm{~m} \times 10 \mathrm{~m}$ grid spacing in the horizontal direction to ensure that relevant processes could be captured using the coarser grid spacing. These simulations are in general agreement with the results presented here, except for slight differences in the calculated volumes of minerals dissolved and precipitated. We conclude that, because these differences likely arise from the accumulation of very small differences in mineral volume changes over the many thousands more time steps required by the high-resolution simulation, the grid spacing that we have chosen is adequate for the objectives of the present study.

Simulations were mostly run on Itasca, an HP Linux cluster maintained by the University of Minnesota Supercomputing Institute (MSI). A small proportion of the simulations were additionally run on the MSI "lab" Linux clusters. Individual simulations were run on up to 800 cores and took on the order of 5-10 CPU-years (i.e., the number of processors employed multiplied by the amount of calendar time required to complete the simulations) to reach 50 years of simulated time. In total, the simulations performed here generated over $1 \mathrm{~TB}$ of output files, with dolomite simulations requiring generally shorter timesteps than calcite simulations and simulations with lower hydraulic head gradients typically requiring smaller timesteps than higher hydraulic head gradient simulations.

\subsection{Physical properties}

Physical properties of reservoir materials are representative of material properties measured for carbonate reservoir rocks (Table 1). In our simulations, capillary pressure is calculated 
according to (Van Genuchten, 1980):

$$
P_{c}=\frac{1}{\alpha}\left(\left(s_{l, e}\right)^{1 / m}-1\right)^{(1-m)},
$$

where $\alpha$ and $m$ are fitting parameters and $s_{l, e}$ is the effective saturation of the wetting phase, defined by:

$$
s_{l, e}=\frac{s_{l}-s_{l, r}}{1-s_{l, r}},
$$

where $s_{l, r}$ is the residual saturation of the liquid phase. Relative permeability of the liquid phase, $k_{r}$, is then calculated according to the Mualem (1976) relative permeability function:

$$
k_{r}=\sqrt{s_{l, e}}\left(1-\left(1-s_{l, e}^{1 / m}\right)^{m}\right)^{2} .
$$

Relative permeability properties are approximated to be those of the Dogger aquifer presented by André et al. (2007), except residual $\mathrm{CO}_{2}$ saturation is set to 0 , instead of the reported value of 0.05 . The different residual $\mathrm{CO}_{2}$ saturation is used here both because PFLOTRAN time steps become prohibitively small when a residual $\mathrm{CO}_{2}$ saturation greater than 0 is employed, and because the nature of our study dictates that fresh brine will flood $\mathrm{CO}_{2}$-saturated zones relatively rapidly and redissolve $\mathrm{CO}_{2}$ trapped in large pores. Permeability is set to $1 \times 10^{-13} \mathrm{~m}^{2}$, which is approximately two orders of magnitude higher than core-scale dolomite permeabilities measured by Tutolo et al. (2014b) and Luhmann et al. (2014), in order to account for the fact that carbonate aquifers deemed feasible for CCUS operations are likely considerably more permeable at the simulated scale (e.g., André et al., 2007, 2010; Randolph and Saar, 2011c; U.S.G.S., 2013).

For all simulations, an initially uniform temperature of $100^{\circ} \mathrm{C}$ is assigned to the simulated domain. This fixed temperature corresponds to a relatively high geothermal gradient of $\sim 50^{\circ} \mathrm{C} / \mathrm{km}$ for a 200 bar reservoir pressure and an extreme geothermal gradient of $\sim 100^{\circ} \mathrm{C} / \mathrm{km}$ for a 100 bar pressure, although we show below that mineral solubilities are relatively pressureindependent. Thus, to reduce further expansion of the parameter space, we have decided to maintain the same temperature for both simulated pressures. For reference, the continental average geotherm is $\sim 25-30^{\circ} \mathrm{C}$, and geothermal reservoir locales range from $\sim 24-76^{\circ} \mathrm{C} / \mathrm{km}$ (Tester et al., 2006). The designated reservoir pressure (e.g., 100 or 200 bars) is assigned to the top row of elements at the furthest upstream end of the simulated reservoir and the rest of the reservoir is allowed to hydrostatically equilibrate according to the designated hydraulic head gradient prior to initialization. At these temperatures and pressures, $\mathrm{CO}_{2}$ is in a supercritical state and therefore has a more liquid-like density than at surface temperatures and pressures (e.g., Benson and Cole, 2008) and a more gas-like dynamic viscosity, resulting in a considerably 
Table 1: Fluid and Heat Flow Parameters

\begin{tabular}{lc} 
Parameter & Value \\
\hline Permeability $\left(\mathrm{m}^{2}\right)$ & $1 \times 10^{-13}$ \\
Aqueous species diffusion coefficient $\left(\mathrm{m}^{2} / \mathrm{s}\right)$ & $1 \times 10^{-9}$ \\
Porosity & $0.07^{\S}$ \\
Van Genuchten $m$ & $0.6^{\dagger}$ \\
Van Genuchten $\alpha$ & $1.9 \times 10^{-6 \dagger}$ \\
$\mathrm{H}_{2} \mathrm{O}$ Resid. Sat. $\left(\mathrm{s}_{l, r}\right)$ & $0.2^{\dagger}$ \\
$\mathrm{CO}_{2}$ Resid. Sat. & $0^{*}$ \\
Max. P (bar) & $100^{\dagger}$ \\
Formation Density $\left(\mathrm{g} / \mathrm{cm}^{3}\right)$ & $2.65^{\sharp}$ \\
Formation Thermal Conductivity $(\mathrm{W} /(\mathrm{m} . \mathrm{K}))$ & $2.5^{\dagger}$ \\
Rock specific Heat $(\mathrm{kJ} /(\mathrm{kg} . \mathrm{K})$ & $1.0^{\sharp}$
\end{tabular}

${ }^{\S}$ Computed from XRCT data (Luhmann et al., 2014) and only accounts for pores $\gtrsim 8 \mu \mathrm{m}$ in diameter

$\dagger^{\dagger}$ André et al. (2010). Dry and wet values are assumed to be identical *See Sect. 2.2

${ }^{\sharp}$ Randolph and Saar (2011a) 
higher mobility (i.e., lower kinematic viscosity) than water (Randolph and Saar, 2011a). These properties allow supercritical $\mathrm{CO}_{2}$ to more efficiently fill subsurface pore space and more efficiently extract heat from the subsurface, respectively (Randolph and Saar, 2011a; Adams et al., 2014). It is important to note here that temperature and pressure both increase according to the regional geothermal gradient, such that real-world CCUS reservoirs at different depths are very likely to have different temperatures.

\subsection{Chemical properties}

In PFLOTRAN, equilibrium between the solution and supercritical $\mathrm{CO}_{2}$ is assumed in elements where supercritical $\mathrm{CO}_{2}$ exists, which is reasonable due to the rapid kinetics of $\mathrm{CO}_{2}$ dissolution and exsolution at the modeled temperature and pressure conditions (Hirai et al., 1997; Takemura and Yabe, 1999). Likewise, the distribution of aqueous species is assumed to be kinetically rapid and at equilibrium according to the aqueous species equilibrium constants within the thermodynamic database. Simulated reservoir brines contain $1 \mathrm{~mol} / \mathrm{kg} \mathrm{NaCl}$, which allows for simulation of the effects of reservoir ionic strength on aqueous species transport while remaining within the limits of applicability of the extended Debye-Hückel equation employed by PFLOTRAN (Tutolo et al., 2015b). In addition, the reservoir brines are equilibrated with the host mineralogy prior to initalizing the simulations. Initial compositional conditions for the calcite and dolomite reservoirs are listed in Table 2.

\subsubsection{Kinetic considerations}

Classically, carbonate dissolution and growth rates have been fit to the empirical relation (Lasaga, 1981; Shiraki and Brantley, 1995; Arvidson and Mackenzie, 1999; Teng et al., 2000):

$$
r=k(\Omega-1)^{n},
$$

where $r$ is the reaction rate, $k$ is the reaction rate constant, $\Omega$ is saturation index (i.e., the ratio of ion activity product to the equilibrium constant for the specified reaction), and $n$ is the affinity factor, set by the reaction mechanism (Lasaga, 1981; Nielsen, 1984; Shiraki and Brantley, 1995). The temperature dependence of $k$ is approximated according to the Arrhenius relationship (e.g., Lasaga, 1981):

$$
k=k_{25} \exp \left(-\frac{E_{A}}{R}\left(\frac{1}{T_{K}}-\frac{1}{298.15}\right)\right),
$$

where $E_{A}$ is the activation energy, $k_{25}$ is the $25^{\circ} \mathrm{C}$ reaction rate constant, and $T_{K}$ is absolute temperature in Kelvin. Because one of the focus minerals in the present study is dolomite, the often-made approximation in which mineral dissolution rate constants are equivalent to their 


\begin{tabular}{lcc} 
Component & $\begin{array}{c}\text { Dolomite } \\
\text { Conc. }(\mathrm{mol} / \mathrm{kg})\end{array}$ & $\begin{array}{c}\text { Calcite } \\
\mathrm{Ca}\end{array}$ \\
$\mathrm{Cl}$ & $1.539 \times 10^{-4}$ & $4.52 \times 10^{-4}$ \\
$\mathrm{CO}_{2}(\mathrm{aq})$ & $3.089 \times 10^{-4}$ & $4.52 \times 10^{-4}$ \\
$\mathrm{Mg}$ & $1.539 \times 10^{-4}$ & - \\
$\mathrm{Na}$ & 1.0 & 1.0 \\
$\mathrm{pH}$ & $8.24^{*}$ & $8.35^{*}$ \\
\hline Mineral volume fraction & 0.93 & 0.93 \\
Reactive surface area $\left(\mathrm{cm}^{2} / \mathrm{g}\right)$ & 70.5 & 70.5 \\
Porosity & 0.07 & 0.07 \\
\hline
\end{tabular}

${ }^{*} \mathrm{pH}$ is set by equilibrium with respect to

reservoir mineral

precipitation rate constants cannot be employed. By comparing calculated results with the experimental dolomite precipitation rate data of Arvidson and Mackenzie (1999), Hellevang et al. (2013) have shown that this approximation dramatically overestimates dolomite precipitation rates at CCUS reservoir temperatures, especially at relatively high dolomite saturation indices. To accommodate this behavior, we modified the PFLOTRAN source code to accept separate values of $r, E_{A}$, and $n$ for both the dissolution and precipitation regimes, and the Arvidson and Mackenzie (1999) parameterization of Eqn. 4 is employed to describe dolomite precipitation rates. Specifically, we set $k_{25}=4.48 \times 10^{-19} \mathrm{~mol} / \mathrm{m}^{2} / \mathrm{s}, \mathrm{E}_{A}=133.47 \mathrm{~kJ} / \mathrm{mol}$, and $n=2.26$. At the elevated temperatures investigated in this study, calcite dissolution and precipitation and dolomite dissolution are sufficiently rapid (see, e.g., Pokrovsky et al., 2009; Hellevang et al., 2013) such that the fluid and mineral equilibrate between time steps, and kinetics therefore do not need to be explicitly considered. However, because PFLOTRAN requires kinetic parameters for each phase included in the simulations, we set rate parameters for these reactions to be sufficiently high such that equilibrium is achieved during each time step. In practice, absolute values of $\Omega$ for these reactions never deviate more than a few tenths of a percent from unity.

In order to facilitate the separation of "primary" calcite and dolomite from "reprecipitated" calcite and dolomite (i.e., minerals that precipitated as a result of the system perturbation 
by $\mathrm{CO}_{2}$ injection), the PFLOTRAN thermodynamic database we employ contains a secondary mineral with identical thermodynamic properties to the primary phase. The primary phase is given an extreme affinity threshold in order to effectively prevent its re-precipitation. The secondary phase, however, is allowed to dissolve if it becomes undersaturated during the course of the simulation.

Specific surface area for both calcite and dolomite is assumed to be $70.5 \mathrm{~cm}^{2} / \mathrm{g}$, which is the value determined by Tutolo et al. (2014b) for whole-core dolomite dissolution rates, based on low- $T$ dissolution rate parameters provided by Pokrovsky et al. (2009). For the kinetically rapid reactions listed above, the magnitude of this parameter is insignificant. However, surface area plays a major role in the calculated volumes and rates of dolomite precipitation, as discussed in Sect. 4.1. The value we employ $\left(70.5 \mathrm{~cm}^{2} / \mathrm{g}\right)$ is approximately half of the geometric surface area calculated by Pokrovsky and Schott (2001) for powdered dolomite, which is consistent with the fact that Tutolo et al. (2014b) derived this value from intact dolomite cores, where preferential flow paths prevent homogenously distributed reactions. Similarly, Li et al. (2014) have shown that mineral effective surface area can be orders of magnitude lower than measured specific surface area.

\subsection{Model runs}

A total of 21 simulations designed to examine the effect of thermal and hydraulic head gradients in carbonate CCUS reservoirs are presented in this contribution (Table 3). Three hydraulic head gradients $(0.01,0.05$, and $0.1 \mathrm{~m} / \mathrm{m}$, corresponding to Darcy velocities of $1.1,5.5$, and $10.9 \mathrm{~m} / \mathrm{yr}$, respectively, for the permeability utilized in this study) are examined for both calcite and dolomite reservoirs with an initial temperature of $100^{\circ} \mathrm{C}$. In each of these scenarios, $50 \mathrm{~kg} / \mathrm{s}\left(1.6 \mathrm{MT} /\right.$ year) of $50^{\circ} \mathrm{C} \mathrm{CO}_{2}$ is injected into the $100^{\circ} \mathrm{C}$ reservoir for 10 years and the reservoir is allowed to recover for an additional 40 years. The effect of pressure (i.e., depth) is investigated by repeating simulations at reservoir pressures of both 100 and 200 bars. The three 200 bar calcite reservoir simulations are additionally repeated with a $\mathrm{CO}_{2}$ injection temperature identical to the reservoir temperature in order to delineate the effects of thermal perturbations on calculated mineral volume changes. In addition, the effect of $\mathrm{CO}_{2}$ injection rate is examined by repeating the three 200 bar calcite reservoir simulations with an injection rate of $4 \mathrm{~kg} \mathrm{CO}_{2} / \mathrm{s}$ (0.13 $\left.\mathrm{MT} \mathrm{CO}_{2} / \mathrm{yr}\right)$. Finally, we present the results of three simulations that examine the effects of reactive surface area and porosity on our presented conclusions (Sect. 4.1). 
Table 3: Summary of model runs

\begin{tabular}{|c|c|c|c|c|c|}
\hline Mineral & $\begin{array}{c}\text { Reservoir } \mathrm{T} \\
\left({ }^{\circ} \mathrm{C}\right)\end{array}$ & $\begin{array}{l}\text { Injection } \mathrm{T} \\
\left({ }^{\circ} \mathrm{C}\right)\end{array}$ & $\begin{array}{l}\text { Injection Rate } \\
\qquad(\mathrm{kg} / \mathrm{s})\end{array}$ & $\begin{array}{c}\text { Reservoir P } \\
\text { (bar) }\end{array}$ & $\begin{array}{l}\text { Hydraulic Head Gradient } \\
\qquad(\mathrm{m} / \mathrm{m})\end{array}$ \\
\hline \multirow[t]{12}{*}{ Calcite } & 100 & 50 & 50 & 100 & 0.1 \\
\hline & & & & & 0.05 \\
\hline & & & & & 0.01 \\
\hline & & & & 200 & 0.1 \\
\hline & & & & & 0.05 \\
\hline & & & & & 0.01 \\
\hline & & & 4 & & 0.1 \\
\hline & & & & & 0.05 \\
\hline & & & & & 0.01 \\
\hline & & 100 & 50 & & 0.1 \\
\hline & & & & & 0.05 \\
\hline & & & & & 0.01 \\
\hline \multirow[t]{6}{*}{ Dolomite } & 100 & 50 & 50 & 100 & 0.1 \\
\hline & & & & & 0.05 \\
\hline & & & & & 0.01 \\
\hline & & & & 200 & $0.1^{*}$ \\
\hline & & & & & 0.05 \\
\hline & & & & & 0.01 \\
\hline
\end{tabular}

*An additional 3 simulations are run at this condition in order to examine the effects of reactive surface area and porosity on the calculated results (Sect. 4.1.)

\section{Results}

\subsection{Thermal perturbation}

The thermal evolution of the simulated carbonate CCUS reservoirs over the 10 years of injection time illustrate that injected $\mathrm{CO}_{2}$ tends to thermally equilibrate with the host reservoir before traveling large distances from the injection well (Fig. 2). This is indicated by the fact that the region outlined by the translucent gray in these figures, which represents the portion of the reservoir containing $>1 \% \mathrm{CO}_{2}$ saturation, is, for the most part, outside of the depressed-temperature, near-well region. At the early stages of injection, as the $\mathrm{CO}_{2}$ plume is approaching its steady-state configuration, the injected $\mathrm{CO}_{2}$ approaches thermal equilibrium 
with respect to the background reservoir temperature before it is transported more than a few meters away from the injection well. $\mathrm{CO}_{2}$ dissolution into the reservoir brine is an exothermic process, which tends to increase the temperature in elements at the plume boundary by up to $\sim 2^{\circ} \mathrm{C}$. The small magnitude of this temperature increase is consistent with the results of other researchers (e.g., André et al., 2010). Joule-Thomson cooling is less apparent than the exothermic dissolution reactions, but is documented below in Sect. 3.3.1. Once the plume is established, the lower relative permeability of water resulting from the increased $\mathrm{CO}_{2}$ pore space saturation allows the injected $\mathrm{CO}_{2}$ plume to "self-insulate" against the advecting, hightemperature fluids, such that the region of the reservoir with temperatures lower than the initial temperature expands slowly with time. Nonetheless, even at the end of the ten-year injection period, the region in which the injection of cool $\mathrm{CO}_{2}$ appreciably decreases (i.e., $>10^{\circ} \mathrm{C}$ lower than the initial reservoir temperature) the reservoir temperature is confined to a near-well region that grows to a maximum of several tens of meters in diameter over the 10-year injection period. After the conclusion of the 10-year $\mathrm{CO}_{2}$ injection period, the $\mathrm{CO}_{2}$ migrates downgradient out of the reservoir. During this period, the reservoir is relatively quick to recover to its initial, unperturbed temperature, as illustrated by the temperature distribution after 50 years of simulated time (Fig. 2). During this recovery period, the low-temperature region is attenuated as it advects down-gradient.

Although we have only illustrated the thermal perturbation for the $0.05 \mathrm{~m} / \mathrm{m}$ hydraulic head gradient scenario, these conclusions are largely representative of all simulations performed in this study. In all simulations, the actual thermal depression created by injecting the $50^{\circ} \mathrm{C} \mathrm{CO}_{2}$ at $50 \mathrm{~kg} / \mathrm{s}$ in the reservoir is limited to this near-well region.

\subsection{Magnitude and spatial distribution of the $\mathrm{CO}_{2}$ plume and mineral precipitation}

The magnitudes and spatial distributions of the $\mathrm{CO}_{2}$ plume and mineral precipitation are affected by the pressure and hydraulic head gradient present within the reservoir. In order to quantify the spatial distribution of the precipitated minerals as well as the $\mathrm{CO}_{2}$ plume, we calculate the horizontal distance between each of their centers of mass and the location of the injection well. It is important to reiterate that the injection wells in the $0.01,0.05$, and 0.1 $\mathrm{m} / \mathrm{m}$ hydraulic head gradient reservoirs are placed 700, 400, and $200 \mathrm{~m}$, respectively, from the upstream boundary. For this reason, the distance downstream from the injection well at which the $\mathrm{CO}_{2}$ plume center of mass exits the reservoir is different for the $0.01,0.05$, and $0.1 \mathrm{~m} / \mathrm{m}$ hydraulic head gradient reservoirs (Figs. 4, 6, and 8).

As $\mathrm{CO}_{2}$ is injected into the reservoir, a small fraction dissolves into the reservoir brine 

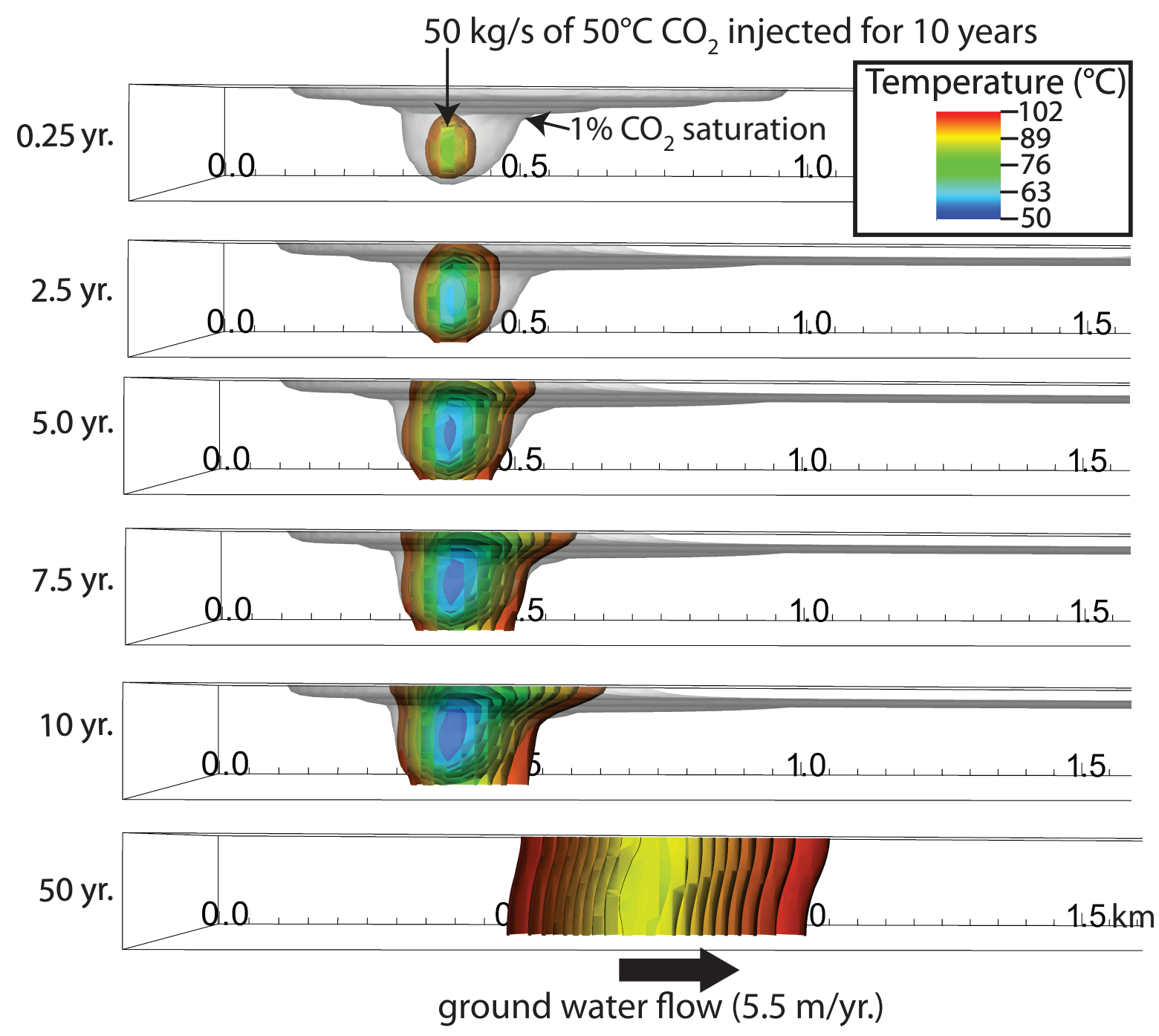

Figure 2: Snapshots of a simulated dolomite CCUS reservoir with a hydraulic head gradient of $0.05 \mathrm{~m} / \mathrm{m}$ at 0.5 , $2.5,5,7.5,10$, and 50 years showing the evolution of temperature as a result of injecting $50 \mathrm{~kg}$ of $50^{\circ} \mathrm{C} \mathrm{CO}_{2}$ per second into a $100^{\circ} \mathrm{C}$ reservoir for 10 years and allowing the reservoir to recover for an additional 40 years. Temperature isosurfaces are cut half way through the simulated reservoir in order to show internal temperatures, and the isosurface for $\mathrm{CO}_{2}$ saturation $>1 \%$ is shown in translucent gray. Note that the simulated reservoir is 2 $\mathrm{km}$ in length but has been cut off in these images for clarity. 

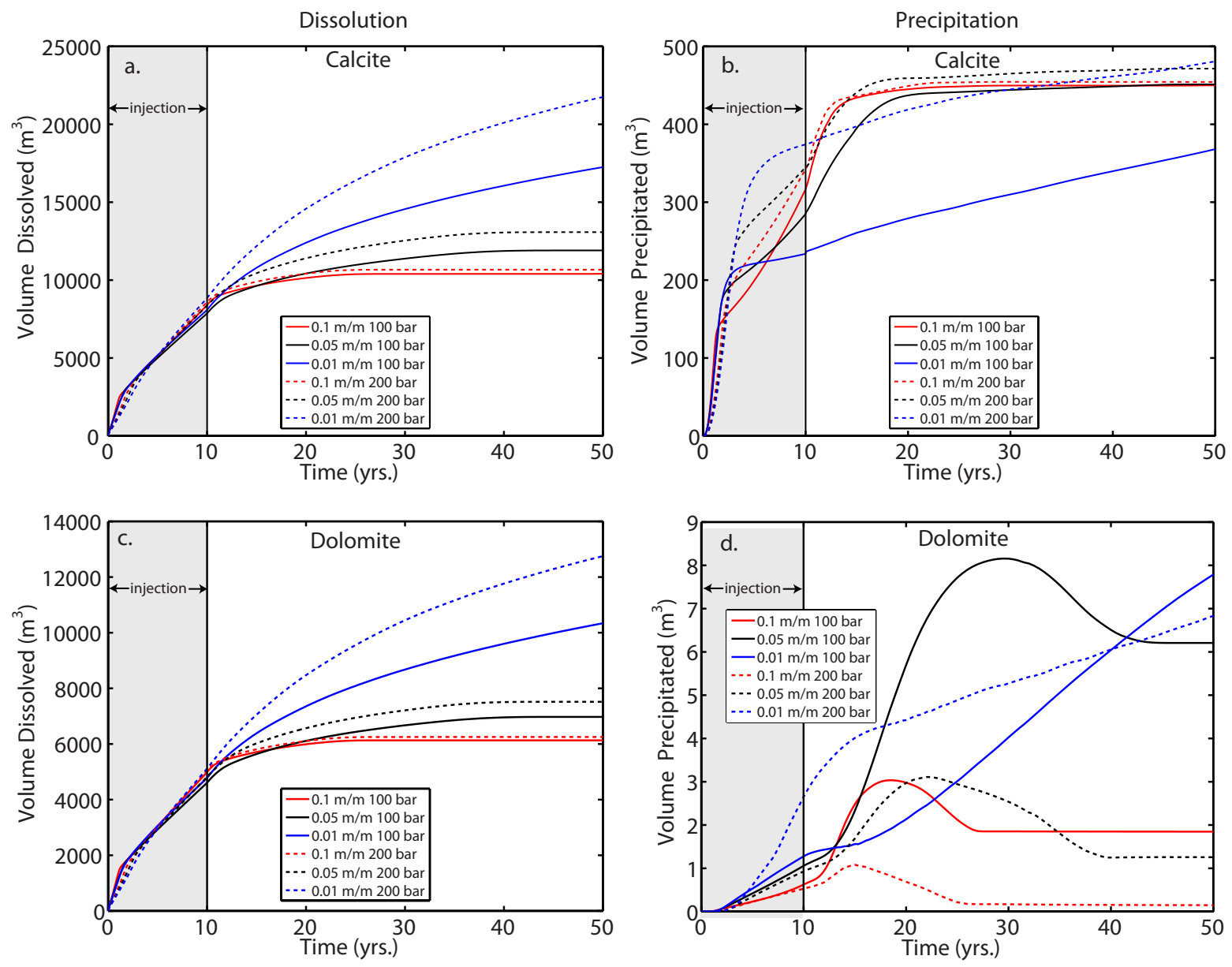

Figure 3: Total volumes of calcite $(\mathrm{a}, \mathrm{b})$ and dolomite $(\mathrm{c}, \mathrm{d})$ dissolution (left column) and precipitation (right column), respectively, resulting from $\mathrm{CO}_{2}$ injection into CCUS reservoirs. $50^{\circ} \mathrm{C} \mathrm{CO}_{2}$ is injected into the simulated $100^{\circ} \mathrm{C}$ reservoirs at a rate of $50 \mathrm{~kg} / \mathrm{s}$ for the first 10 years and the reservoirs are then allowed to recover for 40 subsequent years. Simulations are run for three hydraulic head gradients at both 100 and 200 bar reservoir pressures in order to illustrate the effect of pressure (i.e., depth) on CCUS reservoir evolution. Importantly, the volumes of carbonate minerals that dissolve are several orders of magnitude greater than the volumes of carbonate minerals that precipitate in all simulations. To place these figures in perspective, the element volume employed in these simulations is $4000 \mathrm{~m}^{3}$ and the reservoir volume is $3.6 \times 10^{8} \mathrm{~m}^{3}$. 

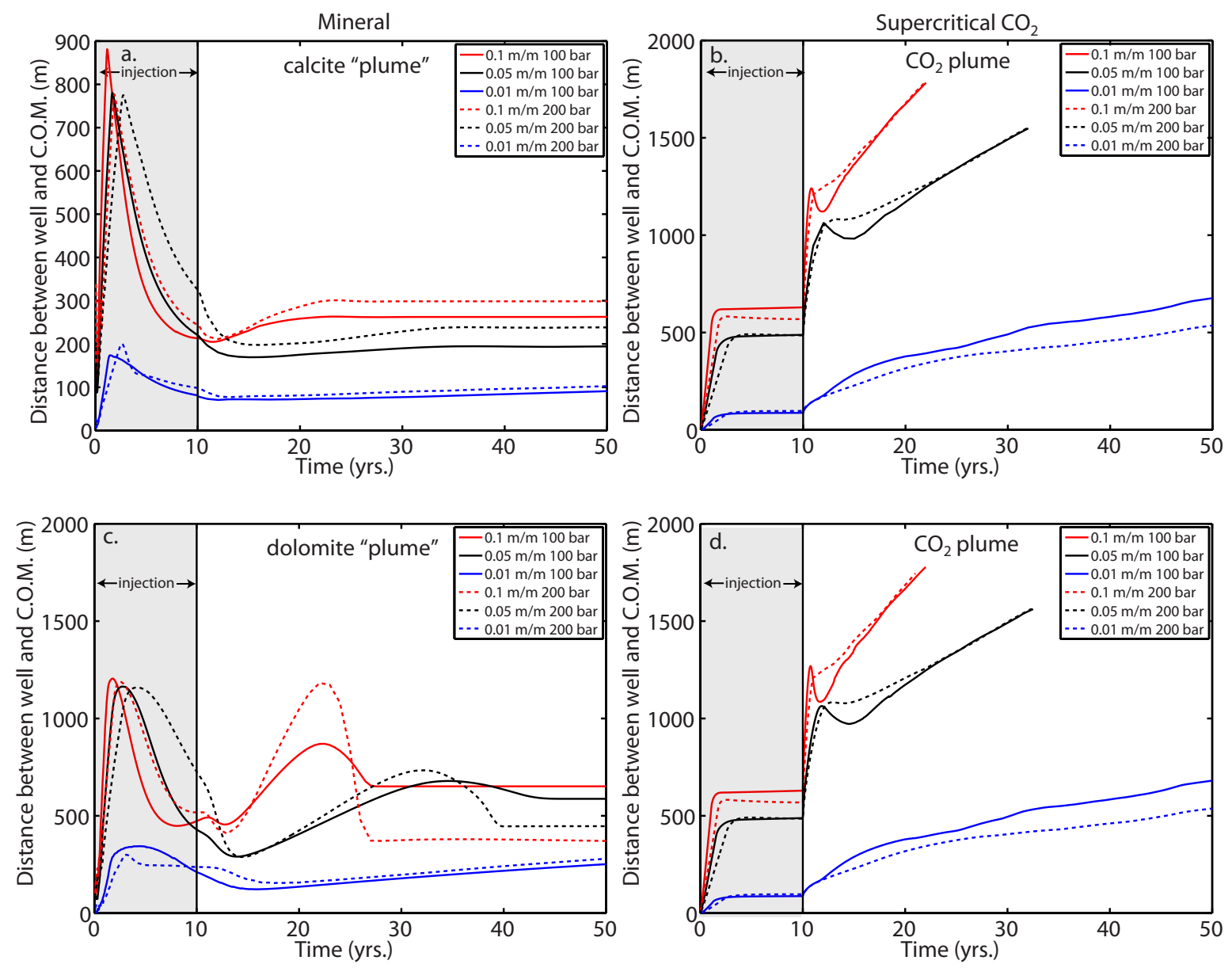

Figure 4: Measure of the horizontal distance between the injection well and center of mass (C.O.M) of mineral $(\mathrm{a}, \mathrm{c})$ and supercritical $\mathrm{CO}_{2}(\mathrm{~b}, \mathrm{~d})$ plumes for simulated calcite $(\mathrm{a}, \mathrm{b})$, and dolomite $(\mathrm{c}, \mathrm{d})$ reservoirs. Simulations are run for three hydraulic head gradients at both 100 and 200 bar reservoir pressures in order to illustrate the effect of pressure (i.e., depth) on CCUS reservoir evolution. Because calcite precipitates at equilibrium and dolomite precipitation is kinetically controlled, the centers of mass of the precipitated calcite "plumes" are considerably closer to the injection well than the analogous dolomite "plume" centers of mass. The supercritical $\mathrm{CO}_{2}$ plumes tend to establish steady-state configurations during the first several years of injection and gradually exit the reservoir once the injection periods have ended. 
and lowers its $\mathrm{pH}$ from the initial, carbonate-buffered value of $\sim 8.2$ to $\sim 4.4$. This lower $\mathrm{pH}$, combined with the higher activity of $\mathrm{CO}_{2}(\mathrm{aq})$ in the $\mathrm{CO}_{2}$-saturated brine, increases the solubility of the reservoir carbonates such that $\mathrm{Mg}$ and $\mathrm{Ca}$ concentrations reach $\sim 12 \mathrm{mmol} / \mathrm{kg}$ in the dolomite simulations and $\mathrm{Ca}$ concentrations reach $\sim 34 \mathrm{mmol} / \mathrm{kg}$ in the calcite simulations. The region affected by these processes generally follows the outline set by the injected $\mathrm{CO}_{2}$ plume, except tends to extend further in the downstream direction. In all presented simulations, the volumes of carbonate phases that dissolve as a result of $\mathrm{CO}_{2}$ injection are much greater than the volumes that precipitate (Fig. 3), although the fact that these dissolved volumes are relatively widespread throughout the reservoir suggests that local changes in reservoir porosity will generally not have a significant effect on reservoir permeability. In the cases of both calcite and dolomite, the maximum volume of the mineral that can dissolve is limited by the volume of brine available in the pore space for reaction, the saturation state of that brine with respect to both $\mathrm{CO}_{2}$ and carbonate phases, and the rate at which the brine is refreshed by non-equilibrated brine. Because the dissolution rates of both phases dictate that the pore fluids equilibrate with the reservoir mineralogy during each time step, the volume of solid that dissolves is transportlimited. In general, the simulated results indicate that the volumes of the carbonate minerals that dissolve during the 10 year injection stage are very similar across all hydraulic head gradient and pressure conditions (Fig. 3).

During the $\mathrm{CO}_{2}$ injection period, an initial, several-year period is required for the supercritical $\mathrm{CO}_{2}$ plume to reach its steady-state configuration and stabilize (Figs. 4, 6, and 8). Once the $\mathrm{CO}_{2}$ plume reaches this configuration, it maintains approximately the same shape (except for elongation in the downstream direction) for the duration of the $\mathrm{CO}_{2}$ injection period and would presumably maintain this configuration as long as the constant $\mathrm{CO}_{2}$ injection rate persists. After $\mathrm{CO}_{2}$ injection is halted, the $\mathrm{CO}_{2}$ plume migrates out of the reservoir such that it exits the reservoirs after $\sim 22$ years in the $0.1 \mathrm{~m} / \mathrm{m}$ head gradient scenario and $\sim 33$ years in the $0.05 \mathrm{~m} / \mathrm{m}$ scenario. In the $0.01 \mathrm{~m} / \mathrm{m}$ scenario, the $\mathrm{CO}_{2}$ plume remains within the simulated reservoirs for the entire 50 years of simulated time.

As the $\mathrm{CO}_{2}$ plume is reaching its steady-state configuration, carbonate minerals are dissolving and precipitating throughout a large fraction of the reservoir. However, as the $\mathrm{CO}_{2}$ plume stabilizes, the region where the minerals precipitate begins to concentration in a region close to the well on the downstream side. Notably, the faster rates of calcite precipitation translate to a relatively stable location of the precipitated calcite plume centers of mass at a distance of 100-300 m downstream from the injection well. However, in the case of the dolomite reservoir, the centers of mass of the precipitated dolomite plumes are consistently farther downstream 
from the injection well, and considerably less stable in their locations. The distance between the centers of mass and the injection well in the $0.1 \mathrm{~m} / \mathrm{m}$ and $0.05 \mathrm{~m} / \mathrm{m}$ lines plotted in Fig. 4 peak two separate times, the first of which is associated with the initial $\mathrm{CO}_{2}$ injection and the second of which is associated with $\mathrm{CO}_{2}$ migration out of the system.

After $\mathrm{CO}_{2}$ injection ceases and the $\mathrm{CO}_{2}$ begins to migrate out of the reservoir, the volume of mineral that dissolves is largely dependent upon the residence time of the $\mathrm{CO}_{2}$ and the associated low-pH, high- $\mathrm{CO}_{2}$ brines in the simulated reservoir. In the high hydraulic head gradient (0.1 $\mathrm{m} / \mathrm{m}$ and $0.05 \mathrm{~m} / \mathrm{m}$ ) calcite reservoirs, the supercritical $\mathrm{CO}_{2}$ is quickly pushed out of the reservoir by inflowing fluid and the dissolution process is virtually halted approximately 10 and 20 years, respectively, after the injection is stopped. In the analogous dolomite simulations, as well as the $0.01 \mathrm{~m} / \mathrm{m}$ head gradient scenarios, the migration of the $\mathrm{CO}_{2}$ plume out of the reservoir is accompanied by a re-dissolution of a portion of the dolomite that had previously precipitated (Fig. 3d).

\subsection{Delineating the effects of temperature, pressure, injection rate, and reservoir size}

\subsubsection{Temperature effects}

In general, the fraction of our $100^{\circ} \mathrm{C}$ reservoirs where $50^{\circ} \mathrm{C} \mathrm{CO}_{2}$ significantly depresses the temperature is limited to a small region in close proximity to the injection well (Fig. 2). The fact that such a minor portion of the reservoir is thermally affected by the cool $\mathrm{CO}_{2}$ injection suggests that, in actuality, only small portions of the reservoir experience the enhanced carbonate solubility associated with low-temperature fluid injection. To quantify the volume of mineral dissolution and precipitation that can be directly attributed to the injection of $50^{\circ} \mathrm{C} \mathrm{CO}_{2}$ versus $100^{\circ} \mathrm{C} \mathrm{CO}_{2}$ into the $100^{\circ} \mathrm{C}$ reservoirs, we present a second set of 200 bar calcite simulations run at all three hydraulic head gradients with $\mathrm{CO}_{2}$ injection at this higher temperature. Under these conditions, it is possible to observe the effects of exothermic $\mathrm{CO}_{2}$ dissolution and Joule-Thomson cooling on reservoir temperature (Fig. 5). In the $100^{\circ} \mathrm{C}$ injection scenarios, Joule-Thomson cooling depresses temperature near the injection well by $\sim 2-3^{\circ} \mathrm{C}$, and exothermic heating increases temperature by $\sim 1-2^{\circ} \mathrm{C}$ near the edges of the supercritical $\mathrm{CO}_{2}$ plume. Similar processes occur in the $50^{\circ} \mathrm{C}$ injection scenarios, but it is more difficult to delineate the cooling effects. The changes in carbonate solubility associated with these temperature changes $\left(<3^{\circ} \mathrm{C}\right.$ in all simulations) are considerably smaller than those associated with a transition from $50^{\circ} \mathrm{C}$ to $100^{\circ} \mathrm{C}$.

In general, the comparison between the $50^{\circ} \mathrm{C}$ and $100^{\circ} \mathrm{C}$ injection scenarios illustrate that the actual mineral volume changes directly attributable to cool $\mathrm{CO}_{2}$ injection are relatively 


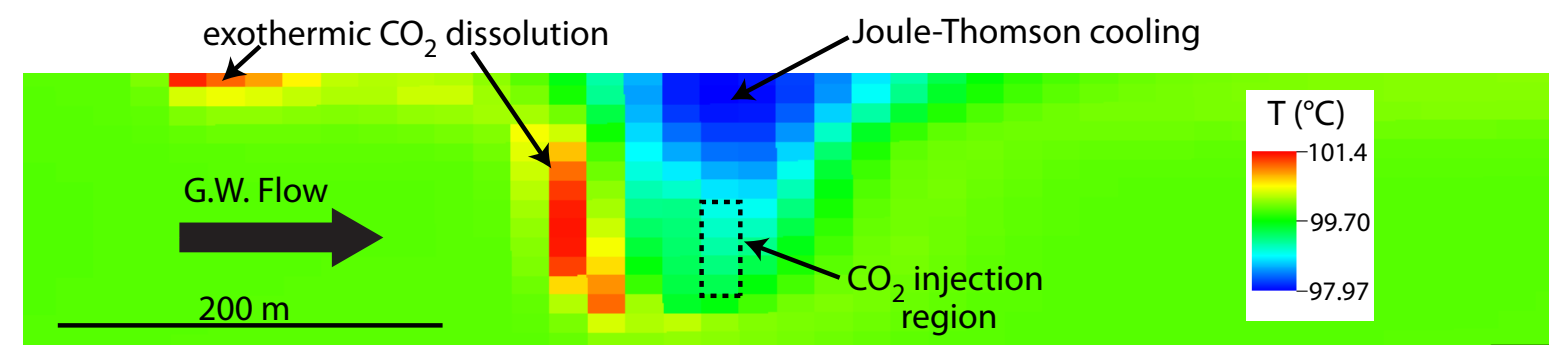

Figure 5: Two-dimensional slice parallel to the dominant flow direction along the center of a 200 bar reservoir with a hydraulic head gradient of $0.05 \mathrm{~m} / \mathrm{m}$ after 5 years of injecting $100^{\circ} \mathrm{C} \mathrm{CO}_{2}$ at $50 \mathrm{~kg} / \mathrm{s}$. The $\mathrm{CO}_{2}$ injection location is outlined in a dashed rectangle. Exothermic $\mathrm{CO}_{2}$ dissolution raises temperature where fresh brine contacts the $\mathrm{CO}_{2}$ plume and Joule-Thomson cooling lowers temperature in the vicinity of the injection well. Exothermic dissolution is most clearly visible at the upstream edge of the plume, where the majority of fresh brine- $\mathrm{CO}_{2}$ equilibration is occurring.

minor (Fig. 6). During the first three years of injection in the 0.1 and $0.05 \mathrm{~m} / \mathrm{m}$ hydraulic head gradient scenarios and for the entire duration of injection in the $0.01 \mathrm{~m} / \mathrm{m}$ hydraulic head gradient scenario, the volumes of calcite precipitation are very similar. This is consistent with dessiccation as the major mode of precipitation during this period and the minor thermal impact that cool $\mathrm{CO}_{2}$ injection has on the reservoir temperature before the steady-state plume configuration is established (Fig. 2). However, once the steady-state plume configuration has been established, the effect of the thermal perturbation on mineral dissolution and precipitation becomes slightly more apparent (Fig. 6a,b).

After 50 years of simulated time, the volume of calcite dissolved in both the $50^{\circ} \mathrm{C}$ and $100^{\circ} \mathrm{C}$ injection simulations are within $\pm 1.7 \%$ of each other (Table 4 ), with the $50^{\circ} \mathrm{C}$ injection scenario tending to dissolve more calcite, except during the later stages of the $0.05 \mathrm{~m} / \mathrm{m}$ hydraulic head gradient scenario ${ }^{1}$. The difference in the volumes of calcite dissolved between the $50^{\circ} \mathrm{C}$ and $100^{\circ} \mathrm{C}$ injection scenarios tends to approximately correspond toto the additional volumes of calcite precipitated in each scenario. Therefore, thermally-induced calcite precipitation approximately doubles the volume of calcite precipitated in the reservoir. However, because the volume of calcite precipitated is, in all cases, less than $5 \%$ of the volume of calcite dissolved, the mineral volume redistribution is strongly dissolution-dominated and permeability changes resulting from calcite precipitation are likely to be practically negligble in both the $50^{\circ} \mathrm{C}$ and $100^{\circ} \mathrm{C}$ injection scenarios.

Although it is counter-intuitive to find that $\mathrm{cool} \mathrm{CO}_{2}$ injection does not dramatically impact

\footnotetext{
${ }^{1}$ The slightly greater calculated percentage of calcite dissolution in the $100^{\circ} \mathrm{C}$ reservoir is likely due to boundary effects and the timing of $\mathrm{CO}_{2}$ exit from the simulated reservoir.
} 

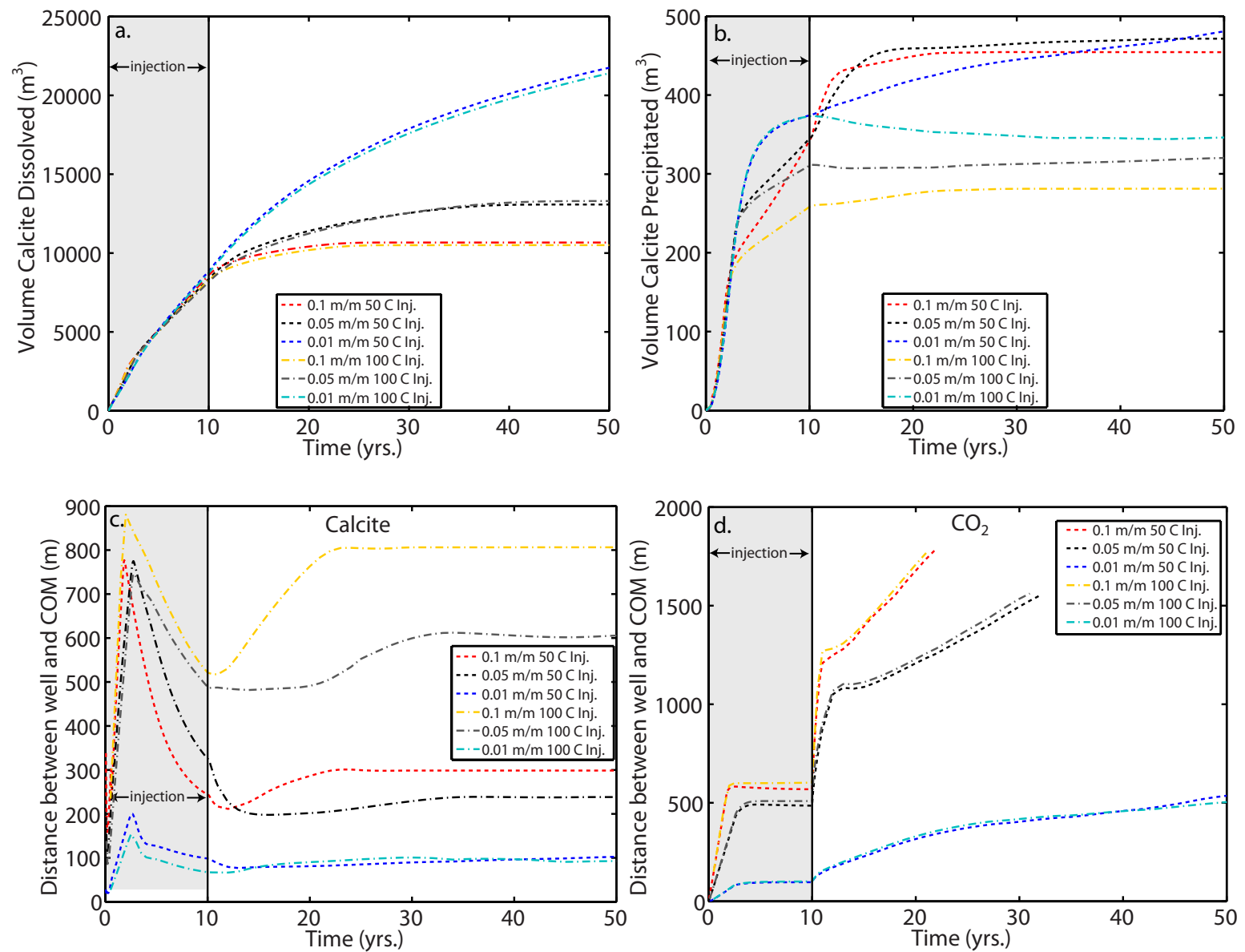

Figure 6: Calcite reservoir simulations were run with simulated injection temperatures of $50^{\circ} \mathrm{C}$ and $100^{\circ} \mathrm{C}$ in order to delineate the effect of $\mathrm{cool} \mathrm{CO}_{2}$ injection into geothermally warm reservoirs. Injection rate $(50 \mathrm{~kg} / \mathrm{s})$, duration (10 years, with 40 years of recovery time), and reservoir temperature $\left(100^{\circ} \mathrm{C}\right)$ and pressure $(200$ bars $)$ were held constant through all simulations. The volumes of calcite dissolved and precipitated (a and b, respectively) as well as the horizontal distances between the centers of mass (C.O.M.s) of the $\mathrm{CO}_{2}$ and precipitated calcite plumes (b and c, respectively) are plotted for comparison. The volumes of calcite dissolved at both injection temperatures are very similar, however the volume of precipitated calcite tends to be higher in the low-temperature injection simulations.

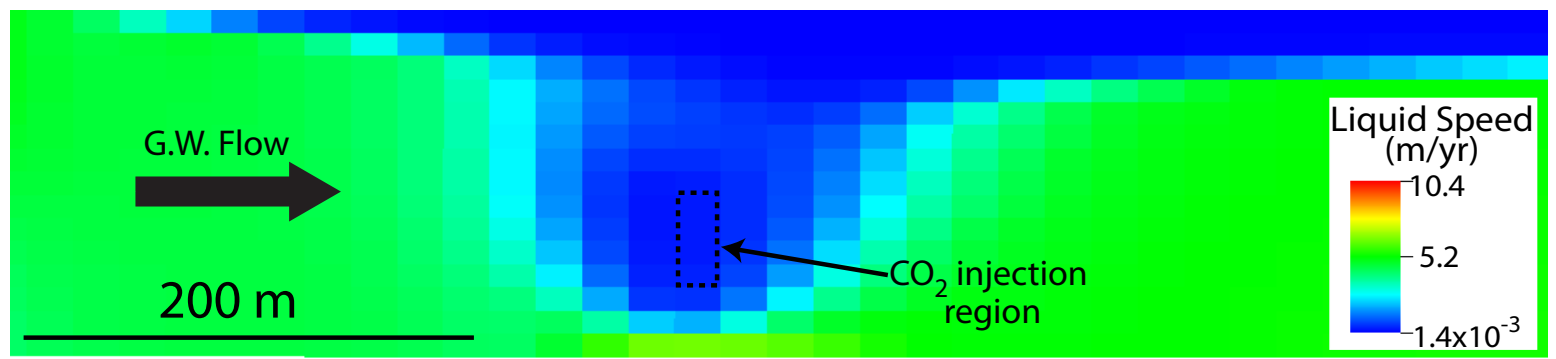

Figure 7: Two-dimensional slice parallel to the dominant flow direction down the center of a 200 bar reservoir with a hydraulic head gradient of $0.05 \mathrm{~m} / \mathrm{m}$ after 5 years of injecting $50^{\circ} \mathrm{C} \mathrm{CO}_{2}$ at $50 \mathrm{~kg} / \mathrm{s}$. Low brine speeds result from relative permeability effects associated with supercritical $\mathrm{CO}_{2}$ saturation of pore space. 
Table 4: Effect of injecting $50 \mathrm{~kg} / \mathrm{s}$ of $\mathrm{CO}_{2}$ at $50^{\circ} \mathrm{C}$ versus $100^{\circ} \mathrm{C}$ into a $100^{\circ} \mathrm{C}, 200$ bar calcite reservoir.

\begin{tabular}{l|ccc|ccc}
\hline \multirow{2}{*}{ Hydraulic head gradient } & \multicolumn{3}{|c|}{ Calcite dissolved $\left(\mathrm{m}^{3}\right)^{\dagger}$} & \multicolumn{3}{c}{ Calcite precipitated $\left(\mathrm{m}^{3}\right)^{\dagger}$} \\
0.01 & $50^{\circ} \mathrm{C} \mathrm{Inj}$. & $100^{\circ} \mathrm{C}$ Inj. & Difference & $50^{\circ} \mathrm{C}$ Inj. & $100^{\circ} \mathrm{C}$ Inj. & Difference \\
0.05 & 21750 & 21400 & $1.6 \%$ & 481 & 346 & $39 \%$ \\
0.1 & 13080 & 13300 & $-1.7 \%$ & 471 & 320 & $47 \%$ \\
\hline
\end{tabular}

${ }^{\dagger}$ Values calculated at end of simulation (50 years).

${ }^{\sharp}$ Difference is calculated as the $50^{\circ} \mathrm{C}$ injection results minus the $100^{\circ} \mathrm{C}$ injection results.

the volumes of calcite dissolved and precipitated in these comparative simulations, the reason for this behavior becomes clear upon closer examination of the velocity profile within the reservoir (Fig. 7). The $\mathrm{CO}_{2}$-brine relative permeability parameters that we employ dictate that once the $\mathrm{CO}_{2}$ pore space saturation reaches $\sim 0.4$, the brine relative permeability drops below $\sim 0.1$. In our simulations, where the maximum $\mathrm{CO}_{2}$ pore space saturation ranges from 0.5 to 0.6 , the brine relative permeability becomes sufficiently low such that the calculated brine velocities are $\sim 0.01 \%$ of the background brine velocity (Fig. 7). Because of these low brine velocities, $\mathrm{CO}_{2}$-equilibrated brine is very slow to travel into and out of the $\mathrm{CO}_{2}$ plume region.

\subsubsection{Pressure effects}

The effect of pressure (depth) is examined by running all simulations for both reservoir types at both 100 and 200 bars of pressure, which correspond to approximate depths of $\sim 1$ and $\sim 2$ $\mathrm{km}$, respectively. At temperatures below $\sim 200^{\circ} \mathrm{C}$, pressure has a negligible effect on the thermodynamics of mineral-fluid and aqueous species reactions (e.g., Helgeson, 1969; Sverjensky et al., 1991; Tutolo et al., 2014a, 2015b). Tutolo et al. (2014b) caculated the solubility of dolomite in $\mathrm{CO}_{2}$-saturated solutions at pressures from 100 to 200 bar and temperatures from 21 to $200{ }^{\circ} \mathrm{C}$ and showed that the effect of pressure on dolomite solubility at these conditions is negligible. Because similar processes govern their solubility, calcite is expected to behave similarly. Therefore, we utilize the same thermodynamic database for simulations at both 100 and 200 bars. Nevertheless, $\mathrm{CO}_{2}$ solubility in aqueous fluids, as well as $\mathrm{CO}_{2}$ density, are pressure-dependent at the conditions considered here (e.g., Duan and Sun, 2003). PFLOTRAN calculates $\mathrm{CO}_{2}$ solubility using a subroutine implementation of the Duan and Sun (2003) model, which allows us to examine the particular effects of pressure on $\mathrm{CO}_{2}$ solubility, $\mathrm{CO}_{2}$ transport in the aqueous phase, and its effect on mineral solubilities. Similar to other reservoir simulators (e.g., TOUGH2-ECO2N (Pruess and Spycher, 2007)), PFLOTRAN utilizes a database of thermo- 
physical properties in order to calculate other properties of $\mathrm{CO}_{2}$ such as enthalpy, density, and viscosity.

The density of supercritical $\mathrm{CO}_{2}$ is strongly pressure-dependent at the temperatures of interest in this study. At low pressure and high temperature, $\mathrm{CO}_{2}$ density tends to be more gas-like, while at higher pressures it tends to be more liquid-like. An equivalent mass of $\mathrm{CO}_{2}$ at lower density will tend to fill a greater fraction of the pore space (Tutolo et al., 2014b), which, when substituted into Eqn. 3, will yield higher relative permeabilities of the $\mathrm{CO}_{2}$ phase. Therefore, the simulated aquifers are more permeable to $\mathrm{CO}_{2}$ at the lower pressures considered in this study even though the same mass of $\mathrm{CO}_{2}$ is injected into the reservoirs in both scenarios. In the higher-pressure scenarios, $\mathrm{CO}_{2}$ is both more soluble and less mobile, and therefore tends to affect the solubility of the carbonate phases to a greater extent. Overall, the effect of pressure on $\mathrm{CO}_{2}$ and mineral soubilities is more pronounced at lower hydraulic head gradients and related lower flow velocities (Fig. 3a,c).

\subsubsection{Effects of $\mathrm{CO}_{2}$ injection rate and reservoir size}

An additional set of 200 bar calcite reservoir simulations that were run with an order of magnitude lower $\mathrm{CO}_{2}$ injection rate $(4 \mathrm{~kg} / \mathrm{s})$ allows us to explore the effect of injection rate on carbonate CCUS reservoir processes. Because the solubility of $\mathrm{CO}_{2}$ in the reservoir brines is virtually the same for the $50 \mathrm{~kg} / \mathrm{s}$ and $4 \mathrm{~kg} / \mathrm{s}$ injection rate scenarios (ignoring the increased pore-fluid pressure that results from injecting $\mathrm{CO}_{2}$ into the reservoir), a significantly greater fraction of the injected $\mathrm{CO}_{2}$ dissolves into the reservoir brine at the lower injection rate. The fact that a smaller volume of $\mathrm{CO}_{2}$ is being injected leads to even less pronounced thermal perturbations associated with $\mathrm{CO}_{2}$ injection compared to the $50 \mathrm{~kg} / \mathrm{s}$ injection rate scenarios.

In general, simulations run with a $\mathrm{CO}_{2}$ injection rate of $4 \mathrm{~kg} / \mathrm{s}$ show very similar trends to those run at $50 \mathrm{~kg} / \mathrm{s}$. The higher injection rate scenarios tend to dissolve more calcite (Fig. 8a), which is consistent with the higher solubility of calcite in $\mathrm{CO}_{2}$-saturated solutions that are occupying a greater proportion of the reservoir. However, the calculated volumes of calcite precipitation show some interesting trends (Fig. 8b). In the $0.01 \mathrm{~m} / \mathrm{m}$ hydraulic head gradient scenario, the volume of calcite precipitated during the final stages of the $4 \mathrm{~kg} / \mathrm{s}$ injection period is considerably higher than that precipitated in the $50 \mathrm{~kg} / \mathrm{s}$ injection scenario. Upon closer examination, it seems likely that this behavior is actually an artifact of the simulated domain size. In the $50 \mathrm{~kg} / \mathrm{s}$ scenario, the supercritical $\mathrm{CO}_{2}$ phase reaches the domain boundary sooner than in the $4 \mathrm{~kg} / \mathrm{s}$ scenario, and, because much of the precipitation is actually occurring through dessiccation at the interface between the injected $\mathrm{CO}_{2}$ and the reservoir brine, the precipitation 
is not captured in the higher injection rate scenario. A similar process appears to be occurring in the $0.05 \mathrm{~m} / \mathrm{m}$ hydraulic head gradient scenarios. Although these results indicate that at least some of the carbonate mineral precipitation is not captured in the presented simulation, it is important to note that these precipitation processes are occurring in a region far removed from the $\mathrm{CO}_{2}$ injection well and therefore will be unlikely to impact $\mathrm{CO}_{2}$ injectivity.

The precipitated calcite and $\mathrm{CO}_{2}$ plumes tend to behave similarly in regards to their spatial distributions (Fig. 8c,d). The precipitated calcite "plume" generally stabilizes in a location further down-gradient from the injection well in the low injection rate scenario (Fig. 8c), which is consistent with the behavior of the $\mathrm{CO}_{2}$ plume (Fig. 8d). As might be expected from consideration of the lower total volume of supercritical $\mathrm{CO}_{2}$ injected into the reservoir, the injected supercritical $\mathrm{CO}_{2}$ tends to completely exit ${ }^{2}$ the simulated domain earlier in the lower injection rate scenarios, as evidenced by the fact that the lines plotted for the $4 \mathrm{~kg} / \mathrm{s}$ injection rate scenarios tend to end at slightly earlier times than those for the $50 \mathrm{~kg} / \mathrm{s}$ scenarios (Fig. 8d). Because the $\mathrm{CO}_{2}$ plume stabilizes farther down-gradient in the lower injection rate scenario and much of the calcite dissolution and precipitation generally occurs at the $\mathrm{CO}_{2}$ /brine interface, calcite precipitates closer to the well in the lower injection rate scenario. The $4 \mathrm{~kg} / \mathrm{s}, 0.01 \mathrm{~m} / \mathrm{m}$ hydraulic head gradient scenario behavior tends to differ from the behavior observed at other hydraulic head gradients, particularly in the calculation of the distance between the calcite plume center of mass and the injection well. This behavior is likely an artifact of the domain size and the timing of the exit of the $\mathrm{CO}_{2}$ plume, and would likely be more similar to the other scenarios if the domain was of sufficient size. Overall, we can conclude that minor effects of mineral dissolution/precipitation on injectivity are seen for both the $4 \mathrm{~kg} / \mathrm{s}$ and $50 \mathrm{~kg} / \mathrm{s} \mathrm{CO}_{2}$ injection rate scenarios.

\section{Discussion}

Although we present a large number of simulations here, several general processes are characteristic to all of them. Firstly, the magnitude of the thermal perturbation caused by cool $\mathrm{CO}_{2}$ injection is relatively limited in all scenarios. This limited thermal perturbation is consistent with the fact that the heat capacity of $\mathrm{CO}_{2}$ is approximately half that of water (Randolph and Saar, 2011a) and it therefore takes a relatively minor amount of the reservoir's geothermal energy to heat the $\mathrm{CO}_{2}$ up to reservoir temperature. Importantly, this property of $\mathrm{CO}_{2}$, combined

\footnotetext{
${ }^{2}$ Note that the reason that the $\mathrm{CO}_{2}$ plume completely exits the simulated reservoirs is an artifact of our usage
} of 0 for the residual $\mathrm{CO}_{2}$ saturation (See Sect. 2.2). 

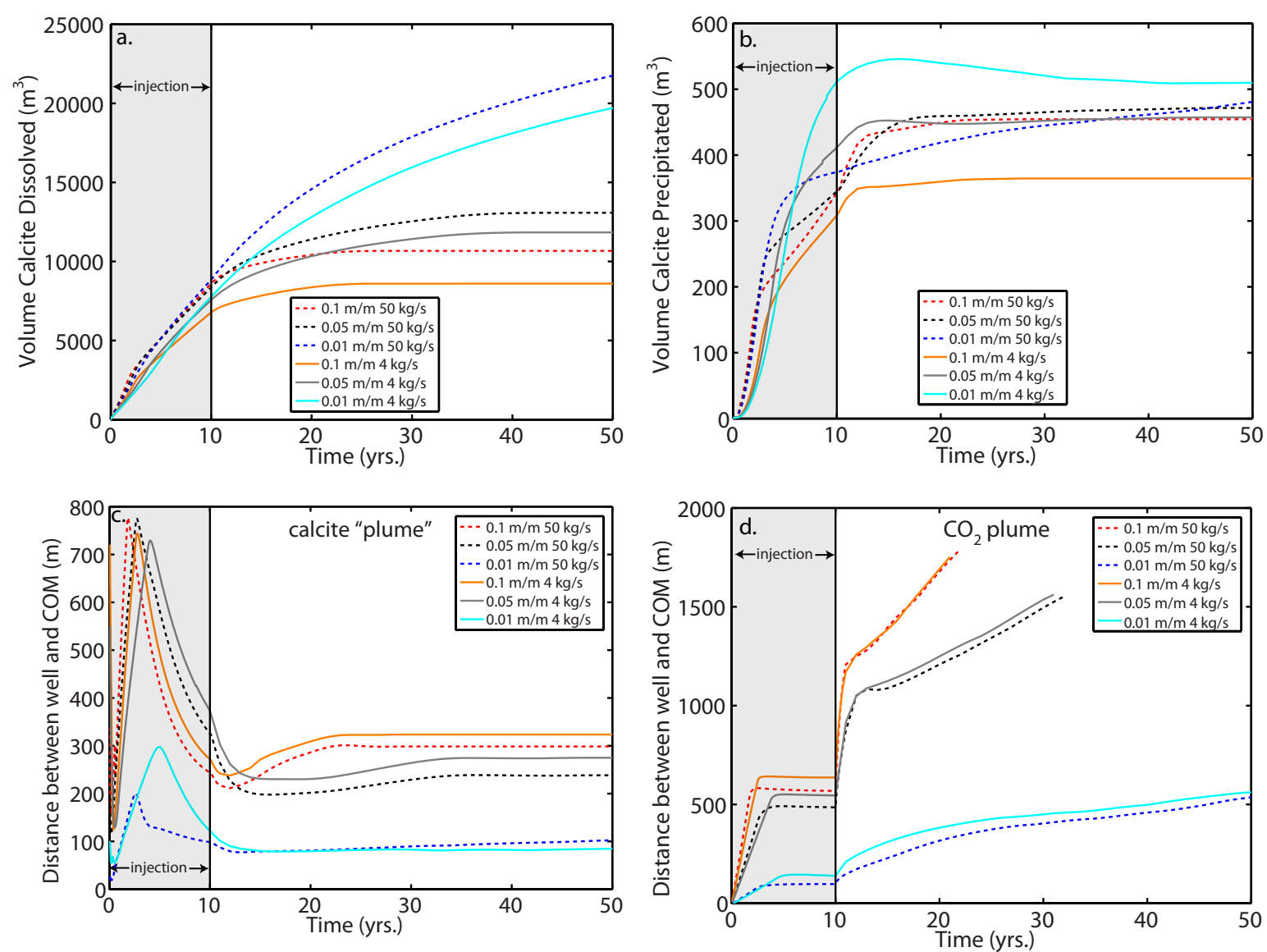

Figure 8: Comparison between 200 bar calcite reservoir simulations performed at a lower injection rate $(4 \mathrm{~kg} / \mathrm{s})$ and those presented in Figs. 3 and 4. Similar to these figures, the summed volume of calcite dissolved (a) and precipitated (b) as well as the horizontal distance between the injection well and centers of mass of precipitated calcite (c) and $\mathrm{CO}_{2}(\mathrm{~d})$ are presented. The higher injection rate simulations tend to both dissolve and precipitate more calcite than the lower injection rate simulations. 
with its higher mobility (i.e., inverse kinematic viscosity), lengthens the period of time that it takes $\mathrm{CO}_{2}$ to deplete a reservoir's heat and allows $\mathrm{CO}_{2}$-based geothermal energy extraction to be longer-lived and more efficient than water-based (e.g., Randolph and Saar, 2011a; Garapati et al., 2015).

Upon $\mathrm{CO}_{2}$ injection, the reservoir brine is displaced and the buoyant $\mathrm{CO}_{2}$ rises towards the low-permeability cap rock, where it pools and expands areally throughout the reservoir. Except for a region that is a maximum of several tens of meters in diameter surrounding the injection well, most of the $\mathrm{CO}_{2}$ is located in a pooled plume beneath the impermeable upper boundary of the simulated reservoir. The vertical extent of this $\mathrm{CO}_{2}$ plume is generally less than about twenty meters, and therefore much of the $150 \mathrm{~m}$ depth of the simulated reservoir contains only single phase brine which may or may not be saturated with respect to the supercritical $\mathrm{CO}_{2}$. However, in thinner reservoirs (e.g., $50 \mathrm{~m}$ ), $\mathrm{CO}_{2}$ injection may cause more widespread displacement throughout the reservoir, similar to plug flow (Garapati et al., 2015).

In general, thermally-induced $\mathrm{CO}_{2}$ exsolution, which was shown to dramatically affect brine relative permeability in a number of laboratory experiments (e.g., Luhmann et al., 2013; Tutolo et al., 2014b) is not readily apparent in any of our simulations. This result is predominantly due to the fact that increases in temperature that affect the $\mathrm{CO}_{2}$-equilibrated brine occur in close proximity to the much larger supercritical $\mathrm{CO}_{2}$ plume (Fig. 2), and the exsolved $\mathrm{CO}_{2}$ therefore simply coalesces with the larger plume. The presence of free-phase supercritical $\mathrm{CO}_{2}$ within the pore space leads to low brine phase velocities within regions with appreciable $\mathrm{CO}_{2}$ saturations (Fig. 7), and therefore the reservoir brine tends to create velocity streamlines that flow around the injection well region and $\mathrm{CO}_{2}$ plume. The displacement of the brine flow pathways around the $\mathrm{CO}_{2}$ plume prevents much of the flowing brine from ever thermally equilibrating with the cool, near-well region. Nonetheless, because our results show that the thermally-impacted region of the reservoir grows over the duration of the injection period (Fig. 2), it is likely that long-term CCUS operations with low $\mathrm{CO}_{2}$ injection temperatures relative to the reservoir temperature will become increasingly thermally perturbed over their lifetime.

Another general characteristic of the presented simulations is that dissolution and precipitation tend to occur in the cells near the interface between the $\mathrm{CO}_{2}$ plume and the reservoir brine. Consistent with the discussion in Sect. 3.3.1, much of the carbonate growth occurs in regions of the reservoir greater than $90^{\circ} \mathrm{C}$. This is generally consistent with the assertion of André et al. (2010) that dessiccation, not thermal processes, accounts for the majority of precipitation when cool $\mathrm{CO}_{2}$ is injected into carbonate reservoirs. Moreover, the majority of the dissolution processes occur at temperatures slightly greater than $100^{\circ} \mathrm{C}$. In these locations, $\mathrm{CO}_{2}$ is dissolv- 
ing into the brine and lowering $\mathrm{pH}$, which enhances carbonate solubility, while, at the same time, exothermic heating is raising the brine temperature and thereby slightly counteracting the increase in carbonate solubility.

A final characteristic trait consistent across all presented simulations is the very small magnitudes of mineral volume changes. Even in the simulation with the largest volume of primary mineral dissolution (200 bar, calcite, $0.01 \mathrm{~m} / \mathrm{m}$ head gradient, see Fig. 3), the grid blockaveraged porosity across the entire reservoir never increases by more than $\sim 0.6 \%$. Furthermore, mineral precipitation reactions tend to account for a maximum of $\sim 0.01 \%$ and $0.0001 \%$ porosity decreases for the calcite and dolomite scenarios, respectively. The rapid equilibration between the injected $\mathrm{CO}_{2}$, reservoir brine, and the host mineralogy leads to much of the simulated reservoirs being characterized by a strong transport limitation (i.e., high Damköler number), wherein the extent of dissolution and precipitation and the associated porosity increases and decreases, respectively, are strongly limited by the rate at which pore space brine is refreshed by a far-from equilibrium fluid (e.g., Steefel and Lasaga, 1990; Steefel et al., 2013; Luhmann et al., 2014). The only exception is dolomite precipitation, which occurs considerably more slowly than calcite precipitation. The slow dolomite precipitation kinetics yield a somewhat lower Damköler number and lead to dolomite supersaturation in fluids that dissolve dolomite at low temperature and travel to the higher-temperature portion of the reservoir. Nonetheless, the fact that calcite dissolves and precipitates at equilibrium in all presented simulations shows that this rate limitation does not dramatically affect our overall conclusion that the pore space-filling potential of the carbonate precipitation reactions are generally quite limited. However, the varied style and extent of these changes could potentially have implications for flow, permeability, porosity, and thermal regimes not considered here (see Sect. 4.1.3).

\subsection{The effect of parameter choice on simulation results}

\subsubsection{Geochemical kinetics}

A number of approximations have been made in the chemical model formulation that may contribute to the overall uncertainty of the simulations presented here. Firstly, although Arvidson and Mackenzie (1999) have made significant strides towards quantifying the rates of dolomite precipitation at conditions relevant to this study, the general process of quantifying precipitation rates is subject to significant uncertainty. The dolomite growth rate parameters we employ were calibrated at dissimilar conditions from those presented here, and the effects of high $\mathrm{pCO}_{2}$ fluids on dolomite precipitation have not yet been quantified. Furthermore, we ignore crystal nucleation rates and assume a constant mineral specific surface area throughout all runs. 

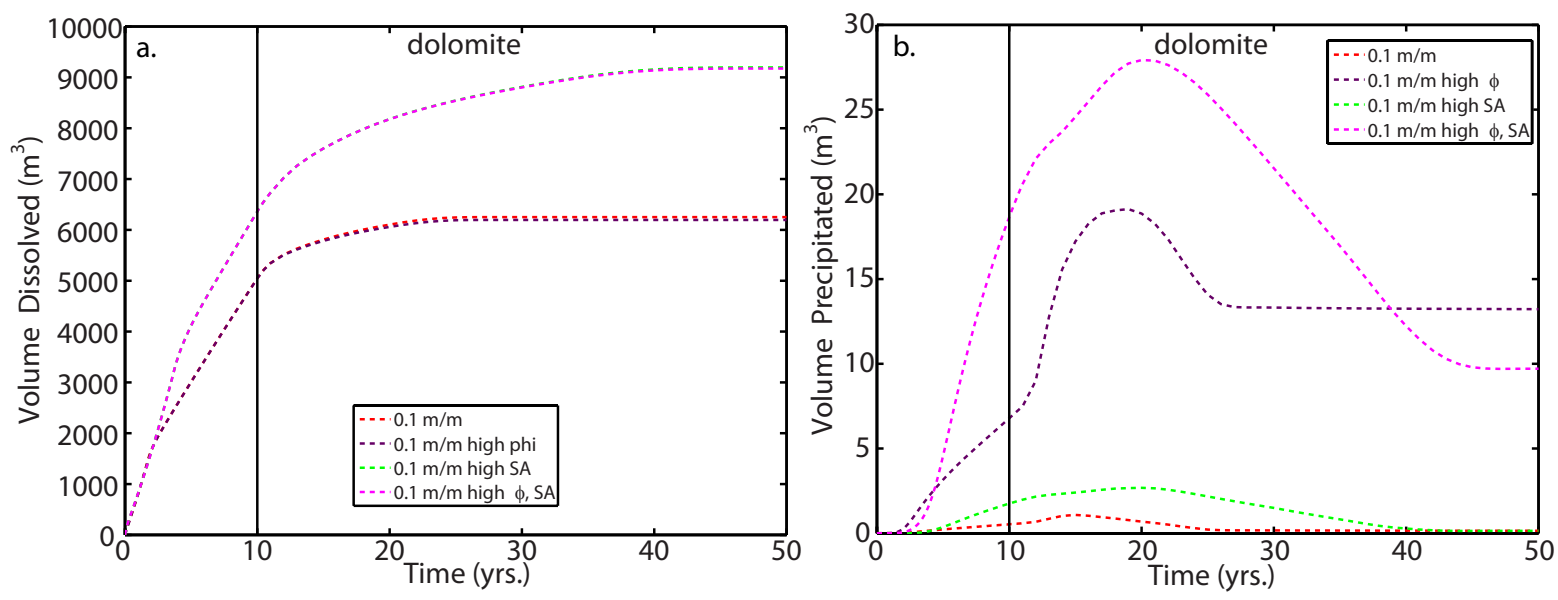

Figure 9: Comparison of volumes of dolomite dissolved (a) and precipitated (b) for simulations run using higher input porosity and surface area than the default parameters utilized in all other simulations. The higher porosity increases the instantaneous water-to-rock ratio and therefore more dolomite must dissolve in order for the fluid to equilibrate. This higher dissolved volume has the effect of increasing the volume of dolomite that precipitates, particularly when a higher surface area of the secondary phase is employed (See Sect. 4.1.1.)

The magnitude of the errors introduced due to these approximations are difficult to estimate. Moreover, mineral reactive surface areas are a perpetual source of uncertainty. The value utilized here, while much lower than those measured using B.E.T. measurements (Luhmann et al., 2014), is utilized due to its agreement with the laboratory dissolution experiment of Tutolo et al. (2014b). To test the effect of our chosen value of surface area, additional dolomite simulations were run by inputing the B.E.T. specific surface area reported by Luhmann et al. (2014) for dolomite rock cores, $1020 \mathrm{~cm}^{2} / \mathrm{g}$ (Fig. 9). Because the rates of geochemical reactions are equivalent to the value of $r$ calculated through Eqn. 4 multiplied by the specific surface area, using this higher value effectively increases the dolomite precipitation rates by around fifteen-fold.

In spite of these limitations associated with dolomite growth kinetics, the simulated reservoir remains transport-limited and the solubility of dolomite in the reservoir fluid still places low upper bound limits on the volume of dolomite that can possibly precipitate. In other words, because the dolomite rapidly dissolves and the fluid reaches equilibrium with respect to dolomite, the volume of dolomite that precipitates is predominantly limited by the amount that dissolves and not necessarily the precipitation rate. Even using these high B.E.T. surface areas and associated higher reaction rates cannot dramatically affect the volume of dolomite that precipitates for the range of investigated model parameters. 


\subsubsection{Porosity, permeability, and relative permeability}

The default porosity that we utilize in our simulations $(0.07)$ is at the lower end of the range of carbonate porosities measured in natural formations (e.g., Schwartz and Zhang, 2003). To examine the effect that porosity, and hence water-to-rock ratio, has on the dissolution and precipitation of carbonate minerals, we present results for the $200 \mathrm{bar}, 50^{\circ} \mathrm{C}, 50 \mathrm{~kg} / \mathrm{s}$ injection dolomite reservoir simulations with a porosity of 0.15 utilizing both the default specific surface area as well as the B.E.T.-measured dolomite specific surface area reported by Luhmann et al. (2014) (Fig. 9). As discussed above, the rate of dolomite dissolution is sufficiently rapid at our simulated temperatures that the fluid equilibrates with dolomite between timesteps. Therefore, the higher specific surface area has no effect on the volume of dolomite dissolved during the simulation (Fig. 9a). However, the larger porosities increase instantaneous water-to-rock ratios so that more dolomite must dissolve before equilibrium can be reached. The higher porosity therefore has the effect of increasing the volume of dolomite that dissolves and precipitates in the reservoir (Fig. 9). Because dolomite precipitation is kinetically limited, the higher surface area has a measurable effect on the precipitated volume of dolomite. However, the volume of dolomite precipitated is still considerably less than the volume of calcite that precipitates in analagous, lower-porosity simulations (Fig. 3), which would therefore be unlikely to affect reservoir injectivity. Notably, a considerable amount of the precipitated dolomite re-dissolves in these simulations, beginning approximately ten years after $\mathrm{CO}_{2}$ injection stops. At this time, the $\mathrm{CO}_{2}$ plume has begun to migrate out of the reservoir and the lower brine relative permeability effects associated with the presence of supercritical $\mathrm{CO}_{2}$ begin to diminish. This higher brine relative permeability and changes in the distribution of the $\mathrm{CO}_{2}$ plume allow more brine to equilibrate with the $\mathrm{CO}_{2}$ plume and enhance the solubility of the previously precipitated dolomite.

It is clear from this discussion, and the discussion about velocity profiles in Sect. 3.3.1 above, that the relative permeabilities of the brine and $\mathrm{CO}_{2}$ phase have a considerable effect on the hydrogeochemical evolution of the simulated CCUS reservoirs. We chose to utilize the relative permeability parameters presented by André et al. (2007), but a considerable body of literature has demonstrated the considerable range of relative permeability parameters associated with different rock types and $\mathrm{CO}_{2}$-brine flow regimes (e.g., Bennion et al., 2008; Müller, 2011; Krevor et al., 2012; Zuo et al., 2012; Falta et al., 2013; Tutolo et al., 2014b). In particular, a number of studies have shown that exsolved $\mathrm{CO}_{2}$ can cause interesting and dramatic relative permeability effects (e.g., Luhmann et al., 2013; Falta et al., 2013; Tutolo et al., 2014b). However, variations in the $\mathrm{CO}_{2}$ and brine relative permeability functions would generally only impact our conclusions 
if they allowed for high relative permeability of the brine phase even in regions with significant $\mathrm{CO}_{2}$ saturation, which is generally not the case.

All simulations performed in the present study utilize a single, isotropic value of permeability for the entire simulated reservoir. However, in real carbonate CCUS reservoirs, the geologic history of the reservoir will likely result in significantly anisotropic and heterogeneous permeability fields. The effect that such heterogeneities have on the conclusions of this study are difficult to quantify. However, regardless of the reservoir's permeability structure, the fact that carbonate mineral dissolution and precipitation processes in our simulated reservoirs tend to be strongly transport limited suggests that the calculated volumes of minerals dissolved and precipitated would only be affected if the reservoir permeability were greater than the value we employ.

\subsubsection{Mineralogical heterogeneities, well geometry, and reservoir size}

Generally, carbonate reservoirs are not entirely composed of dolomite or calcite, and instead are more likely to contain varying abundances of these and other carbonate and silicate minerals. Nonetheless, our results also apply to these mineralogically variable reservoirs. Because calcite never becomes supersaturated in the dolomite simulations we can hypothesize that thermally-induced calcite precipitation is likely to be more prominent than dolomite precipitation in reservoirs containing variable abundances of both calcite and dolomite. This is especially true when one considers the relatively slow rate of dolomite precipitation. Furthermore, variable reservoir thickness and alternate geometry of the injection well(s) may additionally impact the distribution of carbonate mineral dissolution and precipitation in CCUS reservoirs (e.g., MacMinn et al., 2010). If, for example, the reservoir was considerably thinner and a vertical injection well were used, the injected $\mathrm{CO}_{2}$ would likely occupy a greater proportion of the reservoir than in the presented simulations (Garapati et al., 2015). The more widespread distribution of $\mathrm{CO}_{2}$ would likely impact the location and quantity of mineral dissolution and precipitation such that greater porosity and permeability changes would occur. If, on the other hand, a horizontal $\mathrm{CO}_{2}$ injection well drilled perpendicular to the dominant flow direction were utilized, the supercritical $\mathrm{CO}_{2}$ would likely be less concentrated in the reservoir and correspondingly lower porosity changes would likely occur. In any case, the 21 scenarios that we have presented sample a range of parameters that are likely representative of typical CCUS reservoirs and emphasize that the porosity effects resulting from cool $\mathrm{CO}_{2}$ injection and coupled carbonate dissolution/precipitation reactions are unlikely to impact CCUS reservoir injectivity. 


\subsection{Comparison with experimental results}

A significant amount of research effort has been directed towards quanitfying the porosity and permeability effects of $\mathrm{CO}_{2}$ injection into carbonate-bearing aquifers. However, in this study, and elsewhere (e.g., Johnson et al., 2004; Xu et al., 2004; Kharaka et al., 2006; Trémosa et al., 2014), the magnitude of these chemical reactions has been put into a more realistic perspective by simultaneously considering the many coupled processes occurring in CCUS reservoirs as $\mathrm{CO}_{2}$ is introduced and removed from the aquifer. A number of important aspects of the reactive transport approach utilized in this study allow for these previous results to be put into a more realistic perspective. Specifically, we illustrate that porosity increases and decreases associated with carbonate dissolution and precipitation in our simulated CCUS reservoirs tend to be less substantial than the majority of experimental studies suggest.

As we discuss above, the relatively small mineral volume changes observed in our simulations are mostly related to transport limitations that characterize our simulated CCUS reservoirs. Intuitively, as fluids approach equilibrium with respect to reservoir minerals, their capacity for further reaction diminishes. Luhmann et al. (2014) showed that relatively high water-torock mass ratios, on the order of 10 to 50, are required to impact dolomite core permeability through dissolution reactions when the reaction fluid is far-from-equilibrium with respect to dolomite. However, it is important to note that many of their sampled fluids were relatively close to equilibrium with respect to dolomite, the mineral comprising their experimental cores. Therefore, over a length scale of $\sim 2.5 \mathrm{~cm}$, a high-temperature experimental fluid was able, in some cases, to reach zero reactivity. If this fluid were then to continue to travel through a much larger-scale dolomite reservoir, it would do so with negligible reactivity and therefore would not be able to dramatically impact the reservoir's injectivity. These processes are characteristic of the transport-limited, high-Damköler number processes we have investigated in our simulations. As we have illustrated, even our highest flow rates did not refresh the reservoir with enough far-from-equilibrium brine to overcome this transport limitation over our simulated time scales, mostly due to the characteristically low relative permeability of the brine phase within the $\mathrm{CO}_{2}$ plume.

Tutolo et al. (2014b) present a similar experiment to those presented by Luhmann et al. (2014), wherein porosity and dissolution pathways were created as a far-from-equilibrium experimental solution approaches equilibrium with respect to a dolomite core at $21^{\circ} \mathrm{C}$ and $60^{\circ} \mathrm{C}$. However, in the Tutolo et al. (2014b) experiment, the experimental temperature was raised such that the fluid that had been equilibrated with $\mathrm{CO}_{2}$ at $21^{\circ} \mathrm{C}$ and dolomite at $60^{\circ} \mathrm{C}$ was allowed to exsolve $\mathrm{CO}_{2}$ and precipitate dolomite within the previously created pore space. The fluid 
was continually recycled through the core, such that, by the time the experiment concluded, a considerable amount of dolomite had re-precipitated in the dissolution pathways previously created at the lower temperatures. In thermodynamic calculations, Tutolo et al. (2014b) suggest that a 1 molal $\mathrm{NaCl}$ fluid equilibrated with dolomite and $\mathrm{CO}_{2}$ at $50^{\circ} \mathrm{C}$ and 200 bar has the capacity to precipitate $\sim 0.58 \mathrm{~cm}^{3}$ dolomite per $\mathrm{kg}$ if it is instantaneously transferred to $100^{\circ} \mathrm{C}$. Similar calculations show that a 1 molal $\mathrm{NaCl}$ fluid equilibrated with calcite and $\mathrm{CO}_{2}$ at $50^{\circ} \mathrm{C}$ and 200 bar has the capacity to precipitate $\sim 0.83 \mathrm{~cm}^{3}$ calcite per $\mathrm{kg}$. In Fig. 10, we plot two simple calculations designed to quantify how these $50^{\circ} \mathrm{C}$, carbonate-saturated fluids would impact the porosity of a $100^{\circ} \mathrm{C}$ rock with an initial porosity of 0.07 . These calculations suggest that $\sim 100$ pore volumes would be required to lower the porosity of the reservoir by several percent, with dolomite taking a larger number of pore volumes than calcite. These calculations are lower-bound estimates because they ignore both the transport distance required to increase the fluid temperature from $50^{\circ}$ to $100^{\circ} \mathrm{C}$ and the kinetics of carbonate precipitation. Nonetheless, if these estimates are put into the context of our reservoir-scale simulations, we can begin to see why the impact of cool $\mathrm{CO}_{2}$ injection is so minor.

At our highest hydraulic head gradient, $0.1 \mathrm{~m} / \mathrm{m}$, the Darcy velocity is $\sim 10.4 \mathrm{~m} / \mathrm{yr}$. If, for simplicity, we consider a fully brine-saturated representative elementary volume (REV) of 1 $\mathrm{m}^{3}$, we can calculate that it would refill approximately 150 times per year at this flow rate. If subjected to the mineral precipitation as calculated in Fig. 10, the porosity and permeability would be dramatically lowered within several years. If, on the other hand, the REV contained $\gtrsim 40 \%$ supercritical $\mathrm{CO}_{2}$, relative permeability effects discussed above would cause the REV to be refilled less than once a year. At this rate, it would take hundreds or thousands of years for mineral precipitation to have a substantial effect on porosity. Therefore, the transport limitation associated with relatively fast carbonate reaction rates is made even more severe in CCUS reservoirs by the fact that the relative permeability, and hence velocity of the brine phase in contact with supercritical $\mathrm{CO}_{2}$, tends to be relatively low. The permeability change resulting from these porosity-reducing reactions would therefore probably not take effect until after the relevant injection period. Even relatively minor amounts of precipitation can potentially negatively impact formation permeability, however, if they concentrate in pore throats. In this specific case, these minor precipitated volumes could potentially impact permeability over a CCUS reservoir lifetime. 


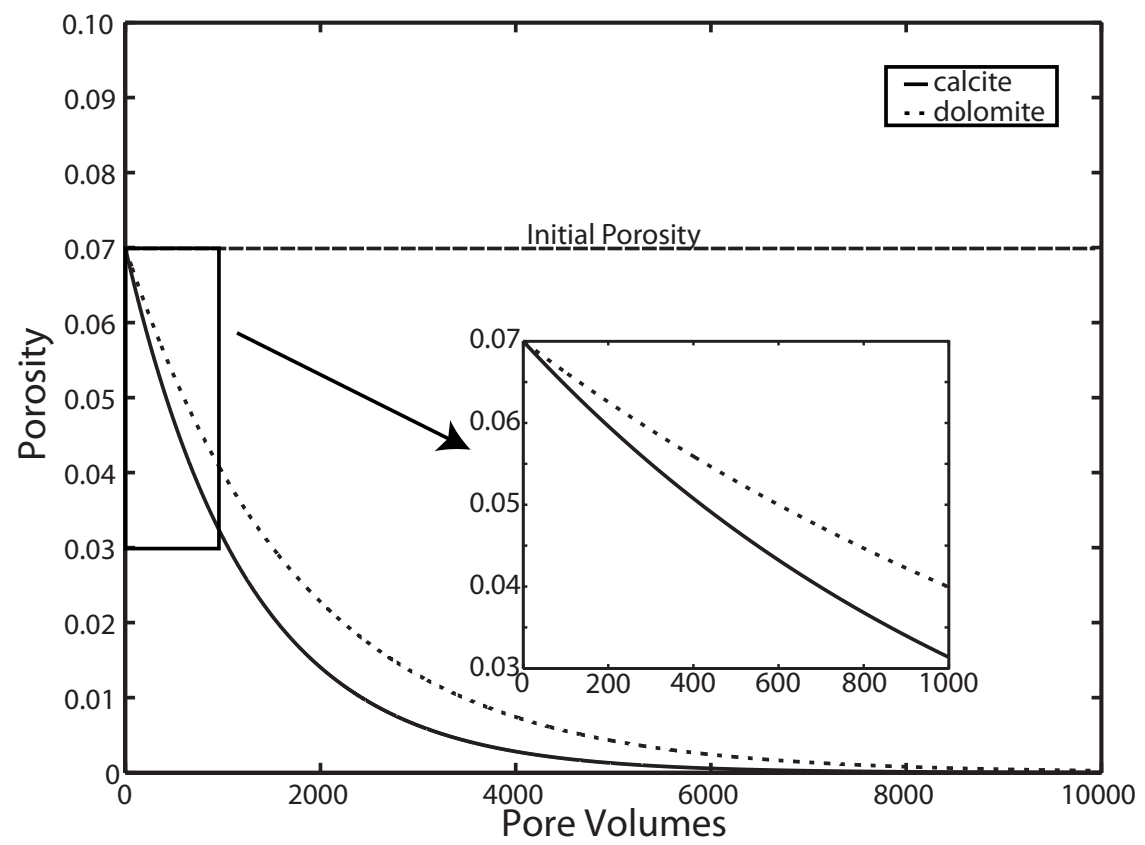

Figure 10: Calculation illustrating the effect of dolomite and calcite precipitation on the porosity of a rock with an initial porosity of 0.07 . The fluid is assumed to instantaneously transfer from $50^{\circ} \mathrm{C}$ to $100^{\circ} \mathrm{C}$ at 200 bar of pressure and deposit $0.58 \mathrm{~cm}^{3} / \mathrm{kg}$ (dolomite) or $0.83 \mathrm{~cm}^{3} / \mathrm{kg}$ calcite (Tutolo et al., 2014b). Porosity evolution is taken into account such that pore volumes become considerably smaller as the porosity is decreased by mineral precipitation. Note that we utilize pore volumes, which decrease as the volume of precipitated mineral increases, instead of water-to-rock ratios in order to preserve the non-dimensionality of the associated equations. 


\subsection{The utility of reactive transport simulations at reservoir scales}

A major conclusion of this study is the benefit of employing reactive transport simulations to upscale experimental results and equilibrium thermodynamic calculations to the field scale. As has been emphasized here, the coupled processes of brine and $\mathrm{CO}_{2}$ flow, $\mathrm{CO}_{2}$ dissolution into and exsolution out of brine, mineral dissolution and precipitation, and the transport of solutes and heat are necessary to consider when examining $\mathrm{CO}_{2}$ injection into carbonate CCUS reservoirs. Only careful examination of all relevant processes in coupled form over (close-to) actual reservoir scales in three dimensions at realistic time scales can reveal these complex processes and their interdependencies. This ultimately requires reactive transport simulations that can put laboratory experiments, that are necessarily conducted over small spatial and temporal scales, as well as field data, which often provide spatially limited information and only a temporal "snapshot", in a more realistic, reservoir-scale framework, both spatially and temporally. Because of their ability to observe the coupled processes of fluid, heat, and aqueous species transport and coupled chemical reactions, reactive transport simulators are a vital tool for the evaluation of CCUS reservoirs. We could not have arrived at the unique conclusions of this study regarding the effect of cool $\mathrm{CO}_{2}$ injection and $\mathrm{CO}_{2}$-brine-carbonate mineral reactions in CCUS reservoirs without using this fully coupled, reactive transport approach.

\section{Conclusions and general implications for CCUS reservoirs}

Because carbonate minerals and $\mathrm{CO}_{2}$ are considerably more soluble at lower temperatures, researchers have hypothesized that cool $\mathrm{CO}_{2}$ injection can effectively redistribute reservoir porosity and permeability and affect injectivity by dissolving carbonates where cold fluids are injected into the reservoir and precipitating carbonates as the injected fluids heat up during flow away from the injection well. In this study, we examine the coupled effects of cool $\mathrm{CO}_{2}$ injection and background hydraulic head gradients on reservoir-scale mineral volume changes using the fully coupled, massively parallel reactive transport simulator PFLOTRAN. We examine the effects of temperature, pressure, hydraulic head gradient, and $\mathrm{CO}_{2}$ injection rate on dissolution and precipitation processes in monomineralic calcite and dolomite CCUS reservoirs. Based on the 21 low-temperature and isothermal $\mathrm{CO}_{2}$ injection simulations we present, we provide the following general conclusions:

1. The low heat capacity of $\mathrm{CO}_{2}$ effectively prevents low-temperature $\mathrm{CO}_{2}$ injection from decreasing the temperature across large portions of the simulated carbonate reservoirs. 
2. The small observed thermal perturbation and generally low relative permeability of brine within supercritical $\mathrm{CO}_{2}$-saturated pore space result in limited mineral dissolution and precipitation directly attributable to cool $\mathrm{CO}_{2}$ injection.

3. Relatively high water-to-rock ratios would be required to substantially affect fluid injectivity through thermally-induced mineral dissolution and precipitation, which may occur over much longer CCUS reservoir lifetimes or in materials that maintain sufficiently high brine relative permeability within the $\mathrm{CO}_{2}$ plume during the $\mathrm{CO}_{2}$ injection period.

4. Fully coupled, reservoir-scale reactive transport simulations are an effective means of placing laboratory- and field-scale observations into a reservoir-scale context, both spatially and temporally.

Furthermore, in order to examine the effect of our chosen porosity and mineral specific surface area on our conclusions, we present an additional set of simulations run with higher porosity and mineral surface area. Nonetheless, even these simulations illustrate the minor effect that low-temperature $\mathrm{CO}_{2}$ injection has on reservoir porosity.

\section{Acknowledgements}

We gratefully acknowledge support from the Department of Energy (DOE) Geothermal Technologies Program under Grant Number EE0002764 and from the Initiative for Renewable Energy and the Environment (IREE), a signature program of the Institute on the Environment (IonE) at the University of Minnesota (UMN) for this contribution and related research. MOS also acknowledges support for this and related research from an NSF Sustainable Energy Pathways (SEP) grant, NSF SEP-1230691, and is grateful for the support of the Hydrogeology and Geofluids research group by the George and Orpha Gibson Endowment. MOS also thanks the Werner Siemens Foundation for its support of the Geothermal Energy and Geofluids group in the Institute of Geophysics, Department of Earth Sciences, ETH-Zürich, Zürich, Switzerland. BMT acknowledges receipt of the UMN Doctoral Dissertation Fellowship, which provided funding for a portion of this research. This work was carried out using computing resources at the University of Minnesota Supercomputing Institute (MSI). Any opinions, findings, conclusions, or recommendations in this material are those of the authors and do not necessarily reflect the views of the DOE, NSF, IREE, IonE, MSI, ETH-Zürich, or UMN. Glenn Hammond and Peter Lichtner are additionally acknowledged for their assistance with PFLOTRAN input files. Associate Editor Jens Birkholzer and two anonymous reviewers are gratefully thanked for 
their handling and helpful comments, which helped to improve the quality and impact of this manuscript.

\section{Disclaimer}

Dr. Saar has a significant financial and business interest in TerraCOH, Inc., a company that may commercially benefit from the results of this research. The University of Minnesota has the right to receive royalty income under the terms of a license agreement with TerraCOH, Inc. These relationships have been reviewed and managed by the University of Minnesota in accordance with its conflict of interest policies. s

\section{References}

Adams, B. M., Kuehn, T. H., Bielicki, J. M., Randolph, J. B., Saar, M. O., 2014. On the importance of the thermosiphon effect in $\mathrm{CPG}\left(\mathrm{CO}_{2}\right.$ plume geothermal) power systems. Energy 69, 409-418.

André, L., Audigane, P., Azaroual, M., Menjoz, A., 2007. Numerical modeling of fluid-rock chemical interactions at the supercritical $\mathrm{CO}_{2}$-liquid interface during $\mathrm{CO}_{2}$ injection into a carbonate reservoir, the Dogger aquifer (Paris Basin, France). Energy Convers. Manage. 48 (6), 1782-1797.

André, L., Azaroual, M., Menjoz, A., 2010. Numerical simulations of the thermal impact of supercritical $\mathrm{CO}_{2}$ injection on chemical reactivity in a carbonate saline reservoir. Transport Porous Med. 82 (1), 247-274.

Arvidson, R. S., Mackenzie, F. T., 1999. The dolomite problem: control of precipitation kinetics by temperature and saturation state. Am. J. Sci. 299 (4), 257-288.

Bennion, B., Bachu, S., et al., 2008. Drainage and imbibition relative permeability relationships for supercritical $\mathrm{CO}_{2}$ /brine and $\mathrm{H}_{2} \mathrm{~S}$ /brine systems in intergranular sandstone carbonate shale and anhydrite rocks. SPE Reservoir Evaluation \& Engineering 11 (03), 487-496.

Benson, S. M., Cole, D. R., 2008. $\mathrm{CO}_{2}$ sequestration in deep sedimentary formations. Elements 4 (5), 325-331.

Blunt, M., Fayers, F. J., Orr Jr, F. M., 1993. Carbon dioxide in enhanced oil recovery. Energy Convers. Manage. 34 (9), 1197-1204.

Brown, D. W., 2000. A hot dry rock geothermal energy concept utilizing supercritical $\mathrm{CO}_{2}$ instead of water. In: Proceedings of the Twenty-Fifth Workshop on Geothermal Reservoir Engineering, Stanford University, Palo Alto, CA. pp. 233-238.

Buscheck, T. A., Sun, Y., Chen, M., Hao, Y., Wolery, T. J., Bourcier, W. L., Court, B., Celia, M. A., Julio Friedmann, S., Aines, R. D., 2012. Active $\mathrm{CO}_{2}$ reservoir management for carbon storage: Analysis of operational strategies to relieve pressure buildup and improve injectivity. Int. J. Greenh. Gas Con. 6, 230-245.

Buscheck, T. A., Sun, Y., Hao, Y., Wolery, T. J., Bourcier, W., Tompson, A. F., Jones, E. D., Julio Friedmann, S., Aines, R. D., 2011. Combining brine extraction, desalination, and residual-brine reinjection with $\mathrm{CO}_{2}$ storage in saline formations: Implications for pressure management, capacity, and risk mitigation. Energy Procedia 4, 4283-4290.

DePaolo, D. J., Cole, D. R., Navrotsky, A., Bourg, I. C., eds., 2013. Geochemistry of geologic $\mathrm{CO}_{2}$ sequestration. Rev. Mineral. Geochem. 77. 
Duan, Z., Sun, R., 2003. An improved model calculating $\mathrm{CO}_{2}$ solubility in pure water and aqueous $\mathrm{NaCl}$ solutions from 273 to $533 \mathrm{~K}$ and from 0 to 2000 bar. Chem. Geol. 193 (3), 257-271.

Eccles, J. K., Pratson, L., Newell, R. G., Jackson, R. B., 2009. Physical and economic potential of geological $\mathrm{CO}_{2}$ storage in saline aquifers. Environment. Sci. Tech. 43 (6), 1962-1969.

Elliot, T. R., Buscheck, T. A., Celia, M., 2013. Active $\mathrm{CO}_{2}$ reservoir management for sustainable geothermal energy extraction and reduced leakage. Greenhouse Gas. Sci. Technol. 3 (1), 50-65.

Falta, R. W., Zuo, L., Benson, S. M., 2013. Migration of exsolved $\mathrm{CO}_{2}$ following depressurization of saturated brines. Greenhouse Gas. Sci. Technol. 3 (6), 503-515.

Farajzadeh, R., Ranganathan, P., Zitha, P. L. J., Bruining, J., 2011. The effect of heterogeneity on the character of density-driven natural convection of $\mathrm{CO}_{2}$ overlying a brine layer. Adv. Water Resour. 34 (3), 327-339.

Freifeld, B., Zakim, S., Pan, L., Cutright, B., Sheu, M., Doughty, C., Held, T., 2013. Geothermal energy production coupled with CCS: A field demonstration at the SECARB Cranfield Site, Cranfield, Mississippi, USA. Energy Procedia 37, 6595-6603.

Garapati, N., Randolph, J. B., Saar, M. O., 2015. Brine displacement by $\mathrm{CO}_{2}$, energy extraction rates, and lifespan of a $\mathrm{CO}_{2}$-limited $\mathrm{CO}_{2}$-Plume Geothermal (CPG) system with a horizontal production well. Geothermics 55 , 182-194.

Gozalpour, F., Ren, S., Tohidi, B., 2005. CO 2 EOR and storage in oil reservoir. Oil Gas Sci. Tech. 60 (3), $537-546$.

Hammond, G., Lichtner, P., Lu, C., 2007. Subsurface multiphase flow and multicomponent reactive transport modeling using high-performance computing. In: Journal of Physics: Conference Series. Vol. 78. IOP Publishing, p. 012025.

Hammond, G., Lichtner, P., Lu, C., Mills, R., 2012. PFLOTRAN: Reactive flow and transport code for use on laptops to leadership-class supercomputers. Ebook: Groundwater Reactive Transport Models, ed. F. Zhang, GT Yeh, and JC Parker, 141-159.

Han, W. S., Stillman, G. A., Lu, M., Lu, C., McPherson, B. J., Park, E., 2010. Evaluation of potential nonisothermal processes and heat transport during $\mathrm{CO}_{2}$ sequestration. J. Geophys. Res. 115 (B7), B07209.

Harlow, F. H., Pracht, W. E., 1972. A theoretical study of geothermal energy extraction. J. Geophys. Res. 77 (35), $7038-7048$.

Helgeson, H. C., 1969. Thermodynamics of hydrothermal systems at elevated temperatures and pressures. Am. J. Sci. 267 (7), 729-804.

Hellevang, H., Pham, V. T., Aagaard, P., 2013. Kinetic modelling of $\mathrm{CO}_{2}$-water-rock interactions. Int. J. Greenh. Gas Con. 15, 3-15.

Hirai, S., Okazaki, K., Tabe, Y., Hijikata, K., Mori, Y., 1997. Dissolution rate of liquid $\mathrm{CO}_{2}$ in pressurized water flows and the effect of clathrate films. Energy 22 (2), 285-293.

IPCC, 2005. IPCC Special Report on Carbon Dioxide Capture and Storage. Prepared by Working Group III of the Intergovernmental Panel on Climate Change [Metz, B., O. Davidson, H.C. de Coninck, M. Loos and L.A. Meyer]. Cambridge University Press, Cambridge, UK and New York, USA.

IPCC, 2014. Summary for policymakers. In: Climate change 2014: Impacts, adaptation, and vulnerability. part A: Global and sectoral aspects. Contribution of working group II to the fifth assessment report of the Intergovernmental Panel on Climate Change, [Field, C.B., V.R. Barros, D.J. Dokken, K.J. Mach, M.D. Mastrandrea, T.E. Bilir, M. Chatterjee, K.L. Ebi, Y.O. Estrada, R.C. Genova, B. Girma, E.S. Kissel, A.N. Levy, S. Maccracken, P.R. Mastrandrea, and L.L. White, eds.]. Cambridge University Press, Cambridge, United Kingdom and New York, NY, USA, 1-32. 
Jobard, E., Sterpenich, J., Pironon, J., Corvisier, J., Jouanny, M., Randi, A., 2013. Experimental simulation of the impact of a thermal gradient during geological sequestration of $\mathrm{CO}_{2}$ : The COTAGES experiment. Int. J. Greenh. Gas Con. 12, 56-71.

Johnson, J., Nitao, J., Knauss, K., 2004. Reactive transport modelling of $\mathrm{CO}_{2}$ storage in saline aquifers to elucidate fundamental processes, trapping mechanisms and sequestration partitioning. Geol. Soc. London, Spec. Pubs. 233 (1), 107-128.

Kharaka, Y., Cole, D., Hovorka, S., Gunter, W., Knauss, K., Freifeld, B., 2006. Gas-water-rock interactions in frio formation following $\mathrm{CO}_{2}$ injection: Implications for the storage of greenhouse gases in sedimentary basins. Geology 34 (7), 577-580.

Kong, X.-Z., Saar, M. O., 2013. Numerical study of the effects of permeability heterogeneity on density-driven convective mixing during $\mathrm{CO}_{2}$ dissolution storage. Int. J. Greenh. Gas Con. 19, 160-173.

Krevor, S., Pini, R., Zuo, L., Benson, S. M., 2012. Relative permeability and trapping of $\mathrm{CO}_{2}$ and water in sandstone rocks at reservoir conditions. Water Resour. Res. 48 (2).

Lasaga, A. C., 1981. Rate laws of chemical reactions. Rev. Mineral. 8.

Li, L., Salehikhoo, F., Brantley, S. L., Heidari, P., 2014. Spatial zonation limits magnesite dissolution in porous media. Geochim. Cosmochim. Acta 126, 555-573.

Lichtner, P. C., Hammond, G. E., Lu, C., Karra, S., Bisht, G., Andre, B., Mills, R. T., Kumar, J., 2013. PFLOTRAN User Manual.

Lo Ré, C., Kaszuba, J. P., Moore, J. N., McPherson, B. J., 2014. Fluid-rock interactions in $\mathrm{CO}_{2}$-saturated, granite-hosted geothermal systems: Implications for natural and engineered systems from geochemical experiments and models. Geochim. Cosmochim. Acta 141, 160-178.

Lu, C., Lichtner, P. C., 2005. PFLOTRAN: Massively parallel 3-D simulator for $\mathrm{CO}_{2}$ sequestration in geologic media. In: DOE-NETL Fourth Annual Conference on Carbon Capture and Sequestration.

Lu, M., Connell, L. D., 2008. Non-isothermal flow of carbon dioxide in injection wells during geological storage. Int. J. Greenh. Gas Con. 2 (2), 248-258.

Luhmann, A. J., Kong, X.-Z., Tutolo, B. M., Ding, K., Saar, M. O., Seyfried, Jr., W. E., 2013. Permeability reduction produced by grain reorganization and accumulation of exsolved $\mathrm{CO}_{2}$ during geologic carbon sequestration: A new $\mathrm{CO}_{2}$ trapping mechanism. Environ. Sci. Tech. 47 (1), 242-251.

Luhmann, A. J., Kong, X.-Z., Tutolo, B. M., Garapati, N., Bagley, B. C., Saar, M. O., Seyfried Jr, W. E., 2014. Experimental dissolution of dolomite by $\mathrm{CO}_{2}$-charged brine at $100^{\circ} \mathrm{C}$ and 150 bar: Evolution of porosity, permeability, and reactive surface area. Chem. Geol. 380, 145-160.

MacMinn, C. W., Szulczewski, M. L., Juanes, R., 2010. $\mathrm{CO}_{2}$ migration in saline aquifers. Part 1. capillary trapping under slope and groundwater flow. J. Fluid Mech. 662, 329-351.

Malik, Q. M., Islam, M., et al., 2000. $\mathrm{CO}_{2}$ injection in the Weyburn field of Canada: Optimization of enhanced oil recovery and greenhouse gas storage with horizontal wells. In: SPE/DOE Improved Oil Recovery Symposium. Society of Petroleum Engineers.

Mills, R. T., Hammond, G. E., Lichtner, P. C., Sripathi, V., Mahinthakumar, G. K., Smith, B. F., 2009. Modeling subsurface reactive flows using leadership-class computing. In: Journal of Physics: Conference Series. Vol. 180. IOP Publishing, p. 012062.

Mualem, Y., 1976. A new model for predicting the hydraulic conductivity of unsaturated porous media. Water Resour. Res. 12 (3), 513-522.

Müller, N., 2011. Supercritical $\mathrm{CO}_{2}$-brine relative permeability experiments in reservoir rocks-Literature review 
and recommendations. Transport Porous Med. 87 (2), 367-383.

Navarre-Sitchler, A. K., Maxwell, R. M., Siirila, E. R., Hammond, G. E., Lichtner, P. C., 2013. Elucidating geochemical response of shallow heterogeneous aquifers to $\mathrm{CO}_{2}$ leakage using high-performance computing: implications for monitoring of $\mathrm{CO}_{2}$. Adv. Water Resour., 45-55.

Nielsen, A. E., 1984. Electrolyte crystal growth mechanisms. J. Cryst. Growth 67 (2), 289-310.

Oldenburg, C. M., 2007. Joule-Thomson cooling due to $\mathrm{CO}_{2}$ injection into natural gas reservoirs. Energy Convers. Manage. 48 (6), 1808-1815.

Pacala, S., Socolow, R., 2004. Stabilization wedges: solving the climate problem for the next 50 years with current technologies. Science 305 (5686), 968-972.

Pokrovsky, O. S., Golubev, S. V., Schott, J., Castillo, A., 2009. Calcite, dolomite and magnesite dissolution kinetics in aqueous solutions at acid to circumneutral $\mathrm{pH}, 25$ to $150^{\circ} \mathrm{C}$ and 1 to $55 \mathrm{~atm} \mathrm{pCO}_{2}$ : New constraints on $\mathrm{CO}_{2}$ sequestration in sedimentary basins. Chem. Geol. 265 (1), 20-32.

Pokrovsky, O. S., Schott, J., 2001. Kinetics and mechanism of dolomite dissolution in neutral to alkaline solutions revisited. Am. J. Sci. 301 (7), 597-626.

Pruess, K., 2006. Enhanced geothermal systems (EGS) using $\mathrm{CO}_{2}$ as working fluid-A novel approach for generating renewable energy with simultaneous sequestration of carbon. Geothermics 35 (4), 351-367.

Pruess, K., Spycher, N., 2007. ECO2N-a fluid property module for the TOUGH2 code for studies of $\mathrm{CO}_{2}$ storage in saline aquifers. Energy Convers. Manage. 48 (6), 1761-1767.

Randolph, J. B., 2011. Coupling geothermal energy capture with carbon dioxide sequestration in naturally permeable, porous geologic formations- a novel approach for expanding geothermal energy utilization. Ph.D. thesis, University of Minnesota.

Randolph, J. B., Saar, M. O., 2011a. Combining geothermal energy capture with geologic carbon dioxide sequestration. Geophys. Res. Lett. 38 (10), L10401.

Randolph, J. B., Saar, M. O., 2011b. Coupling carbon dioxide sequestration with geothermal energy capture in naturally permeable, porous geologic formations: Implications for $\mathrm{CO}_{2}$ sequestration. Energy Procedia 4 , 2206-2213.

Randolph, J. B., Saar, M. O., 2011c. Impact of reservoir permeability on the choice of subsurface geothermal heat exchange fluid: $\mathrm{CO}_{2}$ versus water and native brine. In: GRC Transactions. Vol. 35. pp. 521-526.

Rayward-Smith, W., Woods, A. W., 2011. Some implications of cold $\mathrm{CO}_{2}$ injection into deep saline aquifers. Geophys. Res. Lett. 38 (6), L06407.

Ruan, B., Xu, R., Wei, L., Ouyang, X., Luo, F., Jiang, P., 2013. Flow and thermal modeling of $\mathrm{CO}_{2}$ in injection well during geological sequestration. Int. J. Greenh. Gas Con. 19, 271-280.

Saar, M. O., 2011. Review: Geothermal heat as a tracer of large-scale groundwater flow and as a means to determine permeability fields. Hydrogeol. J. 19 (1), 31-52.

Saar, M. O., Randolph, J. B., Kuehn, T. H., the Regents of the University of Minnesota, 2012. Carbon dioxidebased geothermal energy generation systems and methods related thereto. U.S. Patent No. 8,316,955.

Saar, M. O., Randolph, J. B., Kuehn, T. H., the Regents of the University of Minnesota, 2013. Carbon dioxidebased geothermal energy generation systems and methods related thereto. Canada Patent No. 2.753.393.

Saar, M. O., Randolph, J. B., Kuehn, T. H., the Regents of the University of Minnesota, 2014a. Carbon dioxidebased geothermal energy generation systems and methods related thereto. European Patent No. 2406562.

Saar, M. O., Randolph, J. B., Kuehn, T. H., the Regents of the University of Minnesota, Heat Mining Company, L., 2014b. Carbon dioxide-based geothermal energy generation systems and methods related thereto. U.S. 
Pending Patent No. WO2014015307-A1.

Schwartz, F. W., Zhang, H., 2003. Fundamentals of Ground Water. Wiley New York: 576 p.

Shiraki, R., Brantley, S. L., 1995. Kinetics of near-equilibrium calcite precipitation at $100^{\circ}$ C: An evaluation of elementary reaction-based and affinity-based rate laws. Geochim. Cosmochim. Acta 59 (8), 1457-1471.

Singh, A., Baumann, G., Henninges, J., Görke, U.-J., Kolditz, O., 2012. Numerical analysis of thermal effects during carbon dioxide injection with enhanced gas recovery: A theoretical case study for the Altmark gas field. Environ. Earth Sci. 67 (2), 497-509.

Steefel, C. I., Lasaga, A. C., 1990. Evolution of dissolution patterns: Permeability change due to coupled flow and reaction. In: ACS symposium series. Vol. 416. Oxford University Press, pp. 212-225.

Steefel, C. I., Molins, S., Trebotich, D., 2013. Pore scale processes associated with subsurface $\mathrm{CO}_{2}$ injection and sequestration. Rev. Mineral. Geochem. 77 (1), 259-303.

Sverjensky, D. A., Hemley, J. J., D’Angelo, W. M., 1991. Thermodynamic assessment of hydrothermal alkali feldspar-mica-aluminosilicate equilibria. Geochim. Cosmochim. Acta 55 (4), 989-1004.

Takemura, F., Yabe, A., 1999. Rising speed and dissolution rate of a carbon dioxide bubble in slightly contaminated water. J. Fluid Mech. 378, 319-334.

Tao, Z., Clarens, A., 2013. Estimating the carbon sequestration capacity of shale formations using methane production rates. Env. Sci. Tech. 47 (19), 11318-11325.

Teng, H. H., Dove, P. M., De Yoreo, J. J., 2000. Kinetics of calcite growth: Surface processes and relationships to macroscopic rate laws. Geochim. Cosmochim. Acta 64 (13), 2255-2266.

Tester, J. W., Anderson, B. J., Batchelor, A., Blackwell, D., DiPippo, R., Drake, E., Garnish, J., Livesay, B., Moore, M., Nichols, K., et al., 2006. The future of geothermal energy. Impact of Enhanced Geothermal Systems (EGS) on the United States in the 21st Century, Massachusetts Institute of Technology, Cambridge, MA, 372.

Trémosa, J., Castillo, C., Vong, C. Q., Kervévan, C., Lassin, A., Audigane, P., 2014. Long-term assessment of geochemical reactivity of $\mathrm{CO}_{2}$ storage in highly saline aquifers: Application to Ketzin, In Salah and Snøhvit storage sites. Int. J. Greenh. Gas Cont. 20, 2-26.

Tutolo, B. M., Kong, X.-Z., , Saar, M. O., Seyfried, Jr., W. E., 2014a. Internal consistency in aqueous geochemical data revisited: Applications to the aluminum system. Geochim. Cosmochim. Acta 133, 216-234.

Tutolo, B. M., Luhmann, A. J., Kong, X.-Z., , Saar, M. O., Seyfried, Jr., W. E., 2014b. Experimental observation of permeability changes in dolomite at $\mathrm{CO}_{2}$ sequestration conditions. Environ. Sci. Tech. 48 (4), 2445-2452.

Tutolo, B. M., Luhmann, A. J., Kong, X.-Z., Saar, M. O., Seyfried, W. E., 2015a. CO 2 sequestration in feldsparrich sandstone: Coupled evolution of fluid chemistry, mineral reaction rates, and hydrogeochemical properties. Geochim. Cosmochim. Acta 160, 132-154.

Tutolo, B. M., Schaen, A. T., Saar, M. O., Seyfried, Jr., W. E., 2015b. Implications of the redissociation phenomenon for mineral-buffered fluids and aqueous species transport at elevated temperatures and pressures. Appl. Geochem. 55, 119-127.

U.S.G.S., G. C. D. S. R. A. T., 2013. National assessment of geologic carbon dioxide storage resources-results. U.S.G.S. Circular 1386, 41.

Van Genuchten, M. T., 1980. A closed-form equation for predicting the hydraulic conductivity of unsaturated soils. Soil Sci. Soc. Am. J. 44 (5), 892-898.

$\mathrm{Xu}, \mathrm{T}$., Apps, J. A., Pruess, K., 2004. Numerical simulation of $\mathrm{CO}_{2}$ disposal by mineral trapping in deep aquifers. Appl. Geochem. 19 (6), 917-936.

Xu, T., Sonnenthal, E., Spycher, N., Pruess, K., 2006. TOUGHREACT-a simulation program for non-isothermal 
multiphase reactive geochemical transport in variably saturated geologic media: Applications to geothermal injectivity and $\mathrm{CO}_{2}$ geological sequestration. Comput. Geosci. 32 (2), 145-165.

Zhao, R., Cheng, J., 2014. Non-isothermal modeling of $\mathrm{CO}_{2}$ injection into saline aquifers at a low temperature. Environmental Earth Sci., 1-10.

Zhou, X., Burbey, T. J., 2014. Fluid effect on hydraulic fracture propagation behavior: a comparison between water and supercritical $\mathrm{CO}_{2}$-like fluid. Geofluids 14 (2), 174-188.

Zuo, L., Krevor, S., Falta, R. W., Benson, S. M., 2012. An experimental study of $\mathrm{CO}_{2}$ exsolution and relative permeability measurements during $\mathrm{CO}_{2}$ saturated water depressurization. Transport Porous Med. 91 (2), $459-$ 478. 